\title{
Activity-dependent modulation of inhibitory synaptic kinetics in the cochlear nucleus
}

\author{
Jana Nerlich ${ }^{1}$, Christian Keine ${ }^{1}$, Rudolf Rübsamen ${ }^{1}$, R. Michael Burger ${ }^{2}$ and Ivan Milenkovic ${ }^{3 *}$ \\ ' Department of Neurobiology, Faculty of Biosciences, Pharmacy and Psychology, University of Leipzig, Leipzig, Germany \\ ${ }^{2}$ Department of Biological Sciences, Lehigh University, Bethlehem, PA, USA \\ ${ }^{3}$ Department of Physiology, Faculty of Medicine, Carl Ludwig Institute for Physiology, University of Leipzig, Leipzig, Germany
}

\section{Edited by:}

Conny Kopp-Scheinpflug,

Ludwig-Maximilians-University

Munich, Germany

Reviewed by:

Nace L. Golding, The University of Texas, USA

Yong Lu, Northeast Ohio Medical

University, USA

Michael Hideki Myoga,

Ludwig-Maximilians-Universität

München, Germany

*Correspondence:

Ivan Milenkovic, Department of Physiology, Faculty of Medicine,

Carl Ludwig Institute for Physiology, University of Leipzig, Liebigstrasse

27, Leipzig, 04103, Germany

e-mail: Ivan.Milenkovic@

medizin.uni-leipzig.de
Spherical bushy cells (SBCs) in the anteroventral cochlear nucleus respond to acoustic stimulation with discharges that precisely encode the phase of low-frequency sound. The accuracy of spiking is crucial for sound localization and speech perception. Compared to the auditory nerve input, temporal precision of SBC spiking is improved through the engagement of acoustically evoked inhibition. Recently, the inhibition was shown to be less precise than previously understood. It shifts from predominantly glycinergic to synergistic GABA/glycine transmission in an activity-dependent manner. Concurrently, the inhibition attains a tonic character through temporal summation. The present study provides a comprehensive understanding of the mechanisms underlying this slow inhibitory input. We performed whole-cell voltage clamp recordings on SBCs from juvenile Mongolian gerbils and recorded evoked inhibitory postsynaptic currents (IPSCs) at physiological rates. The data reveal activity-dependent IPSC kinetics, i.e., the decay is slowed with increased input rates or recruitment. Lowering the release probability yielded faster decay kinetics of the single- and short train-IPSCs at $100 \mathrm{~Hz}$, suggesting that transmitter quantity plays an important role in controlling the decay. Slow transmitter clearance from the synaptic cleft caused prolonged receptor binding and, in the case of glycine, spillover to nearby synapses. The GABAergic component prolonged the decay by contributing to the asynchronous vesicle release depending on the input rate. Hence, the different factors controlling the amount of transmitters in the synapse jointly slow the inhibition during physiologically relevant activity. Taken together, the slow time course is predominantly determined by the receptor kinetics and transmitter clearance during short stimuli, whereas long duration or high frequency stimulation additionally engage asynchronous release to prolong IPSCs.

Keywords: inhibition, activity-dependent decay, re-uptake, intersynaptic pooling, asynchronous release, spherical bushy cell, cochlear nucleus

\section{INTRODUCTION}

Synaptic inhibition is mainly mediated by glycine and $\mathrm{GABA}_{\mathrm{A}}$ receptors (GlyR and $G A B A_{A} R$, respectively) which tightly regulate neuronal and network activities. While the GlyR-generated inhibitory postsynaptic current (IPSC) is generally endowed with fast decay kinetics (Takahashi et al., 1992; Awatramani et al., 2004), GABA provides slow and in some cases tonic inhibition (Farrant and Nusser, 2005; Capogna and Pearce, 2011; Tang et al., 2011). Notably, there are presynaptic terminals in the sensory systems (Wentzel et al., 1993; Protti et al., 1997; Apostolides and Trussell, 2014), cerebellum (Dumoulin et al., 2001; Rousseau et al., 2012; Husson et al., 2014) and in the spinal cord (Jonas et al., 1998; O'Brien and Berger, 1999; Keller et al., 2001; Seddik et al., 2007) that release both transmitters beyond the early postnatal development. This allows for an additional variability, through activity-dependent use of transmitters (Nerlich et al., 2014), differential distribution of respective receptors at the same cell (Chéry and de Koninck, 1999), at different cells (Dugué et al., 2005; Kuo et al., 2009), or shaping the IPSC decay through action of both glycine and GABA on GlyR (Lu et al., 2008).

The postsynaptic responses in neurons expressing both GlyR and $\mathrm{GABA}_{\mathrm{A}} \mathrm{R}$ usually represent a mixture of respective fast and slow synaptic currents (Russier et al., 2002; Awatramani et al., 2005; González-Forero and Alvarez, 2005; Coleman et al., 2011; Apostolides and Trussell, 2013). The relative contribution of both physiologically important components can change according to the activity pattern (Fischl et al., 2014). Such activitydependent inhibitory control, mediated by dual glycine-GABA signaling, has been recently shown for the spherical bushy cells (SBCs) in the central auditory system (Nerlich et al., 2014). SBCs receive acoustically evoked excitatory input from auditory nerve fibers through large calyceal terminals, the endbulds of Held (Ryugo and Sento, 1991; Isaacson and Walmsley, 1996; Nicol and Walmsley, 2002), and non-primary inhibition from neurons within the cochlear nucleus (Wickesberg and Oertel, 
1990; Saint Marie et al., 1991; Campagnola and Manis, 2014). The amplitude of IPSCs is dominated by GlyRs, while the initially small GABAergic component successively enhances the inhibitory strength and shapes its duration at physiologically relevant rates (Nerlich et al., 2014). Unlike other central auditory synapses that utilize phasic inhibition even at high rates (Awatramani et al., 2004; Kramer et al., 2014), IPSCs in SBCs summate due to slow kinetics (Xie and Manis, 2013, 2014; Nerlich et al., 2014), thereby providing a functionally tonic inhibition, similar to inhibition acting on the granule cells in the dorsal cochlear nucleus (DCN) and nucleus magnocellularis neurons in the cochlear nucleus of the chick ( $\mathrm{Lu}$ and Trussell, 2000; Monsivais et al., 2000; Balakrishnan et al., 2009). To date, the synaptic mechanisms that determine the slow kinetics of the mixed glycine-GABA transmission in SBCs remained elusive.

We examined the mechanisms underlying the slow activitydependent IPSC kinetics in SBCs by performing whole-cell recordings in acute slice preparations of juvenile Mongolian gerbils in combination with synaptic stimulation of inhibitory inputs. Our results demonstrate that the low capacity of glycine and GABA uptake allows transmitter rebinding, particularly at input rates above $100 \mathrm{~Hz}$. The activity-driven transmitter spillover possibly engaged distant GlyR but not GABA $\mathrm{A}$. Synaptic activity largely desynchronized the release of glycine and GABA, which had a significant contribution to the slow IPSC profile.

\section{MATERIALS AND METHODS}

The experimental procedures were approved by the Saxonian district Government Leipzig ( $\mathrm{T}$ 84/12, T 67/13) and conducted according to the European Communities Council Directive (86/609/EEC).

\section{SLICE PREPARATION}

Coronal slices $(180 \mu \mathrm{m})$ containing the rostral anteroventral cochlear nucleus (AVCN) were cut from P22-P30 gerbils of either sex. The brainstem was sliced with a vibratome in low-calcium artificial cerebrospinal fluid (ACSF) solution containing (in $\mathrm{mM}$ ): $125 \mathrm{NaCl}, 2.5 \mathrm{KCl}, 0.1 \mathrm{CaCl}_{2}, 3 \mathrm{MgCl}_{2}, 1.25 \mathrm{NaH}_{2} \mathrm{PO}_{4}, 25$ $\mathrm{NaHCO}_{3}, 25$ glucose, 2 sodium pyruvate, 3 myo-inositol, 0.5 ascorbic acid, continuously bubbled with $5 \% \mathrm{CO}_{2}$ and $95 \% \mathrm{O}_{2}$, $\mathrm{pH}$ 7.4. Slices were incubated in the standard recording solution (ACSF same as for slicing, except $\mathrm{CaCl}_{2}$ and $\mathrm{MgCl}_{2}$ were changed to $2 \mathrm{mM}$ and $1 \mathrm{mM}$, respectively) for $30 \mathrm{~min}$ at $37^{\circ} \mathrm{C}$ and stored at room temperature until recording. Experiments were performed at nearly physiological temperature $\left(33.5 \pm 0.5^{\circ} \mathrm{C}\right)$.

\section{ELECTROPHYSIOLOGICAL RECORDINGS}

Whole-cell patch clamp recordings were performed on SBCs in the rostral pole of the AVCN. Due to their large soma size and localization in the low-frequency area of the gerbil AVCN, these neurons can be visually distinguished from globular bushy cells. Morphological verification of SBCs was done during the recording by intracellular labeling with ATTO 488 and visualization by a CCD camera (IMAGO Typ VGA; TILL Photonics). The pipettes had resistances of 3-4 M $\Omega$ when filled with (mM):
$125 \mathrm{CsMeSO}_{3}, 18$ TEA-Cl, $3 \mathrm{MgCl}_{2}, 10$ HEPES, 0.1 EGTA, 4.5 QX-314-Cl, 5 phosphocreatine, 2 ATP disodium salt, 0.3 GTP disodium salt, and $50 \mu \mathrm{M}$ ATTO 488 ( $\mathrm{pH} 7.3$ with $\mathrm{CsOH}$ ). The resulting inward currents with larger amplitudes enabled more accurate analyses compared to the small events occurring with physiological $\left[\mathrm{Cl}^{-}\right]_{\text {pip }}$. Consistent with slow inhibitory kinetics in the present study, the synaptically evoked hyperpolarizations acquired with gramicidin perforated patch recordings also exhibited slow activity-dependent synaptic decays (gramicidin perforated patch: $\mathrm{t}_{\mathrm{wd}}$ single: $18.5 \pm 4.0 \mathrm{~ms}, 100 \mathrm{~Hz} 10 \mathrm{th}$ IPSC: $42.6 \pm 4.1 \mathrm{~ms}, n=6$, see Nerlich et al., 2014). IPSCs were evoked by electrical stimulation of afferent fibers through a bipolar theta glass electrode (Science Products, tip $\varnothing 5 \mu \mathrm{m}$ ) filled with bath solution and placed at distances of $30-60 \mu \mathrm{m}$ from the cell. Pulse stimuli $(100 \mu \mathrm{s}, 15-90 \mathrm{~V})$ were generated by a stimulator (Master 8 ) and delivered via a stimulus isolation unit (AMPI Iso-flex) to evoke either single events or trainresponses at different frequencies. Voltage clamp measurements were done from $\mathrm{V}_{\text {hold }}=-71 \mathrm{mV}$, (Nerlich et al., 2014), except in cases where the amplitudes of the small asynchronous events were increased for precise event detection by holding the cell at $-81 \mathrm{mV}$ (Figure 5). To isolate glycine- and $\mathrm{GABA}_{\mathrm{A}}$ receptor mediated signals, a pharmacological inhibition of glutamate (50 $\mu \mathrm{M}$ AP-5, $10 \mu \mathrm{M}$ NBQX) and GABA receptors (3 $\mu \mathrm{M}$ CGP $55845)$ was performed in all experiments. Offline correction of voltages was done for junction potentials of $11 \mathrm{mV}$. For some experiments, the extracellular calcium concentration in the ACSF was reduced to $1.2 \mathrm{mM}$ in order to decrease the release probability. In such cases, the magnesium concentration was simultaneously increased to $1.8 \mathrm{mM}$ to maintain the concentration of divalent cations.

\section{DATA AOUISITION AND ANALYSIS}

The recordings were acquired using a Multiclamp 700B amplifier (Molecular Devices). The mean capacitance of the cells was $23.15 \pm 4.34 \mathrm{pF}$ (mean $\pm \mathrm{SD}, n=52)$. The average series resistance was $11.25 \pm 1.56 \mathrm{M} \Omega(n=52)$, which was compensated by $50 \%$ to a remaining Rs of 3-7 M $\Omega$. During experiments the series resistance changed on average by $2.6 \%(n=52)$. Cells with series resistance changes $>10 \%$ were excluded from analysis. There was no correlation between the IPCS amplitudes and decay time constants $\left(r_{\mathrm{s}}=0.17, p=0.22, n=53\right)$. Together with the previously reported lack of correlation between the IPSC amplitudes and rise times $\left(r_{\mathrm{s}}=0.04, p=0.78, n=43\right.$, Nerlich et al., 2014), these data rule out the possible contribution of series resistance error to decay time constant measurements. Recorded signals were digitized at $50 \mathrm{kHz}$ and filtered with a $6 \mathrm{kHz}$ Bessel low-pass filter. Data were examined with pClamp 10 software (Molecular Devices) followed by analyses using custom-written Matlab routines (version 8.3, Mathworks, Natick). Mean amplitudes, $10-90 \%$ rise times and decay time constants of IPSCs were analyzed from averaged traces ( $>5$ repetitions). For detection of asynchronous release events, the current traces were bandpass filtered between 50 and $1500 \mathrm{~Hz}$ using a zero-phase forward and reverse digital IIR filter to remove the decay component (see Figure 5A). Statistical analysis by means of $z$-test revealed events with current amplitudes exceeding 1.96 times $(p<0.05)$ 
the standard deviation of the baseline. To avoid multiple triggers of the same event, all triggers occurring within $5 \mathrm{~ms}$ after the preceding event were excluded from the analysis. The results were visually controlled to ensure the correct detection of spontaneous events. The events occurring prior to electrical stimulation (spontaneous IPSCs) were quantified and compared to events emerging after the end of synaptic stimulation of inhibitory inputs. Asynchronous events were clearly visible during the decay phase of the last evoked IPSC. Events detected by the software during the first $20 \mathrm{~ms}$ of the current decay were not included into the analysis to avoid false positive results. Data from 3 repetitions for each condition were pooled and presented for each cell.

IPSC decay phase was fitted with mono- or bi-exponential functions based on an increase in adjusted $R^{2}$ values. The weighted $\tau$ decay was calculated as $\tau_{\mathrm{wd}}=\left(\mathrm{A}_{\text {fast }} \times \tau_{\text {fast }}+\mathrm{A}_{\text {slow }}\right.$ $\left.\times \tau_{\text {slow }}\right) /\left(A_{\text {fast }}+A_{\text {slow }}\right)$, where $A_{\text {fast }}$ and $A_{\text {slow }}$ are amplitudes at $t=0$ and $\tau_{\text {fast }}$ and $\tau_{\text {slow }}$ are the fast and slow time constants, respectively. In cases of mono-exponential fits, one exponential component was set to 0 .

\section{STATISTICS}

Data sets were compared with the appropriate $t$-test or analysis of variance (ANOVA). The $p$-values of multiple comparisons were adjusted by the Dunn-Šidak procedure. Within-subject comparisons were performed by repeated-measures (RM) ANOVA after testing for sphericity using Mauchly test, and GreenhouseGeissner correction applied as appropriate. ANOVA was used to test for effects of drugs and possible interactions of input frequency and drug superfusion. The changes in asynchronous release evoked by different input frequencies were tested for significance by a $z$-test, $z=(\mathrm{A}-\mathrm{BL}) / \mathrm{SD}_{B L}$, with $\mathrm{A}$ being the average number of events/bin 20-60 ms after stimulation, BL the mean of the baseline ( $1 \mathrm{~s}$ prior to stimulation $=$ spontaneous IPSC level) and $\mathrm{SD}_{B L}$ the standard deviation of the baseline. All data are reported as mean \pm SEM, unless otherwise stated.

\section{RESULTS}

\section{IPSC DECAY RATE IS ACTIVITY-DEPENDENT}

SBCs exhibit slow inhibitory synaptic decays (Figure 1A) mediated by GlyR and $\mathrm{GABA}_{\mathrm{A}} \mathrm{R}$ (gerbil: spontaneous IPSCs: $\tau_{\mathrm{wd}}=16.7 \pm 1.2 \mathrm{~ms}$, synaptically evoked IPSCs $\tau_{\mathrm{wd}}=23.7 \pm 5.3 \mathrm{~ms}$, Nerlich et al., 2014; mouse: spontaneous IPSCs: $\tau_{\mathrm{wd}}=8.75 \pm 0.6 \mathrm{~ms}$, synaptically evoked IPSCs $\tau_{\mathrm{wd}}=11.1 \pm 0.8 \mathrm{~ms}$, Xie and Manis, 2013). Both the glycinergic and the GABAergic components were observed in all pharmacology experiments acquiring IPSCs with suprathreshold stimulation to evoke reliable responses (see also Nerlich et al., 2014). Notably, the pharmacologically isolated glycinergic and GABAergic single events were previously shown to have similar kinetics (Nerlich et al., 2014), thus arguing against the hypothesis that in SBCs the fast decay component can be accounted to glycine and the slow component to GABA. In the present study we investigated the underlying mechanism determining such inhibitory current kinetics. The decay phase of synaptically evoked single IPSCs was best fit with a bi-exponential function with a fast decay time constant $\tau_{\text {fast }}=8.7 \pm 2.1 \mathrm{~ms}$, a slow decay time constant $\tau_{\text {slow }}=38.9 \pm 7.2 \mathrm{~ms}$ and their respective

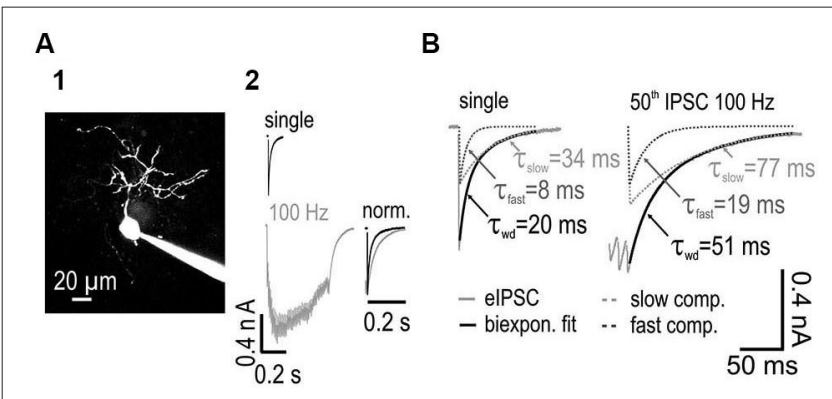

C

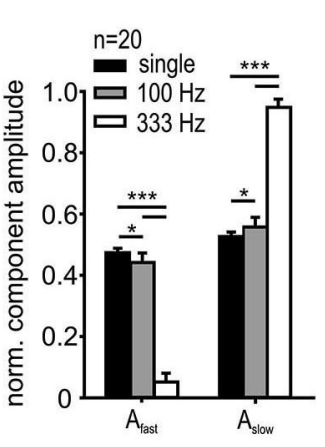

D

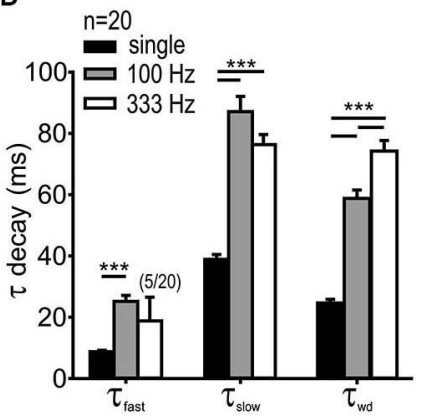

E

1

$\mathbf{F}$

2
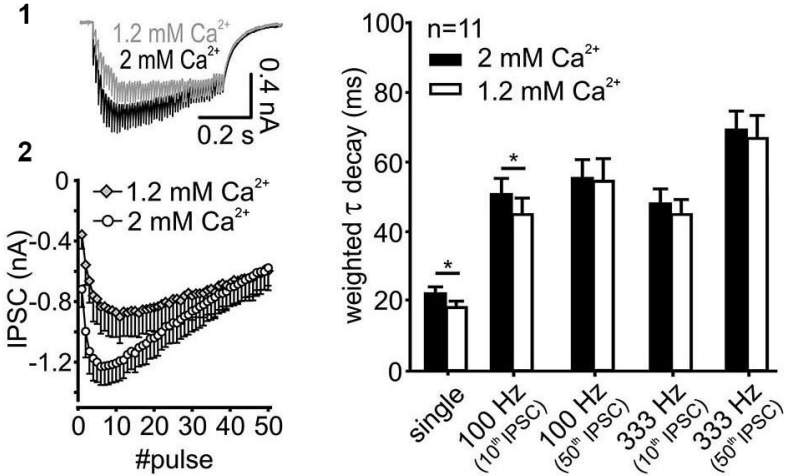

FIGURE 1 | IPSC decay kinetics are activity-dependent. (A1) SBC labeled with ATTO 488 reveals its characteristic morphology. (A2) Exemplary IPSCs elicited by single and $100 \mathrm{~Hz}$ stimulation of synaptic inputs. Right: Superimposed normalized IPSC from single-pulse, and 50-pulse responses, the latter showing decay times prolonged by train stimulation. (B) IPSCs decay was best fit with a bi-exponential function with the decay time constants $\tau_{\text {fast }}$ and $\tau_{\text {slow; }}$ also shown are the respective weighted decay time constants $\tau_{\text {wd }}$ (C) The respective component amplitudes $A_{\text {fast }}$ and $A_{\text {slow }}$ varied systematically with stimulation frequency. The fraction of the slow exponential component increased at higher input frequencies $(n=20$, ${ }^{*} p<0.05,{ }^{* * *} p<0.001$, RM ANOVA) with a complementary decrease in the fast component amplitude. (D) Fast and slow decay time constants at different input frequencies $(n=20)$. Compared to single pulse stimulation, the increased input rate prolonged $\tau_{\text {fast }}$ at $100 \mathrm{~Hz}(p<0.001$, paired $t$-test) and $\tau_{\text {slow }}$ at both $100 \mathrm{~Hz}$ and $333 \mathrm{~Hz}(p<0.001$, RM ANOVA).

Activity-dependent change of the $\tau_{\text {fast }}$ and $\tau_{\text {slow }}$ and the respective amplitudes at $100 \mathrm{~Hz}$ and $333 \mathrm{~Hz}$ (see panel C) resulted in a prolonged $\tau_{w d}$ of repetitive IPSCs ( $p<0.001$, RM ANOVA). (E) The release probability determines the temporal profile and the inhibitory strength at the onset of an IPSC train. (E1) Traces of IPSCs under standard (2 mM, used for slice recordings) and reduced (1.2 $\mathrm{mM}$ ) extracellular calcium concentration. (E2) Mean baseline amplitudes of 50 IPSCs in a $100 \mathrm{~Hz}$ train under different

(Continued) 


\section{FIGURE 1 | Continued}

extracellular calcium concentrations $(n=6)$. (F) For single IPSCs and the 10th IPSC at $100 \mathrm{~Hz}$ the weighted decay time constant was shorter under $1.2 \mathrm{mM}$ extracellular calcium. $\left[\mathrm{Ca}^{2+}\right]_{0}$ had no influence on $\tau_{\mathrm{wd}}$ at longer trains of IPSCs (50 pulses) or at higher input frequency $(333 \mathrm{~Hz})(n=11$, single and $100 \mathrm{~Hz} 10$ th $p<0.05,100 \mathrm{~Hz} 50$ th, $333 \mathrm{~Hz}$ 10th and 50th, $p>$ 0.27 , RM ANOVA).

relative amplitudes $A_{\text {fast }}=0.47 \pm 0.06$ and $A_{\text {slow }}=0.53 \pm 0.06$. The resulting average weighted decay time constant for 20 SBCs was $\tau_{\mathrm{wd}}=24.7 \pm 5.4 \mathrm{~ms}$ (mean $\pm \mathrm{SD}$ ). The synaptic current decays were progressively slower after repetitive stimulation of inputs and with increasing input frequencies (Figures 1B,D). Also, the relative amplitude of the slow exponential component increased with input rates (Figure 1C; $\mathrm{A}_{\text {slow }}$ single $=0.53 \pm 0.06$, $100 \mathrm{~Hz}=0.56 \pm 0.03 ; 333 \mathrm{~Hz}=0.95 \pm 0.03$, single vs. $100 \mathrm{~Hz} p<0.05 ; 100 \mathrm{~Hz}$ vs. $333 \mathrm{~Hz} p<0.001, n=20$, RM ANOVA). Complementary decrease in amplitude of the fast component occurred over the same range of stimuli $\left(A_{\text {fast }}\right.$ single $=0.47 \pm 0.06,100 \mathrm{~Hz}=0.44 \pm 0.03,333 \mathrm{~Hz}=0.05 \pm 0.03)$. The slow decay time constant was prolonged substantially at $100 \mathrm{~Hz}$ and $333 \mathrm{~Hz}$ (Figure 1D; $\tau_{\text {slow }}$ single $=38.9 \pm 1.6 \mathrm{~ms}$, $100 \mathrm{~Hz}=87.1 \pm 5.0 \mathrm{~ms}, 333 \mathrm{~Hz}=76.3 \pm 3.3 \mathrm{~ms}, n=20$, $p<0.001$ for single vs. $100 \mathrm{~Hz}$ and $333 \mathrm{~Hz}, \mathrm{RM}$ ANOVA). At $333 \mathrm{~Hz}$, the decay phase was best fit with a mono-exponential function excluding the fast exponential component in $75 \%$ of recorded SBCs (in these cells $A_{\text {fast }}$ was set to 0 ). Due to the rare occurrence of $\tau_{\text {fast }}$ at $333 \mathrm{~Hz}$ (only in 5 out of 20 cells), this parameter was statistically compared only for the single and $100 \mathrm{~Hz}$ stimulation. The $\tau_{\text {fast }}$ was prolonged at $100 \mathrm{~Hz}$ compared to single pulse stimulation $\left(\tau_{\text {fast }}\right.$ single $=7.1 \pm 0.6$, $100 \mathrm{~Hz}=21.4 \pm 3.0, n=20$, single vs. $100 \mathrm{~Hz} p<0.001$, paired $t$-test). Activity-dependent change of $\tau_{\text {fast }}, \tau_{\text {slow }}$ and the respective amplitudes resulted in a prolongation of $\tau_{w d}$ with increasing input frequency (Figure 1D; $\tau_{\mathrm{wd}}$ single $=24.7 \pm 1.2 \mathrm{~ms}$, $100 \mathrm{~Hz}=58.8 \pm 2.8 \mathrm{~ms}, 333 \mathrm{~Hz}=74.2 \pm 3.5 \mathrm{~ms}, n=20$, $p<0.001$ for all comparisons, RM ANOVA). However, the longer decays were not associated with larger IPSC amplitudes $\left(\tau_{\mathrm{wd}}\right.$ single $=22.8 \pm 0.8 \mathrm{~ms}$, 50th $100 \mathrm{~Hz}=61.8 \pm 2.5 \mathrm{~ms}, n=25$, $p<0.001$, paired $t$-test; IPSC amplitude single $=0.56 \pm 0.5 \mathrm{nA}$, 50 th $100 \mathrm{~Hz}=0.55 \pm 0.04 \mathrm{nA}, n=25, p=0.81$, paired $t$-test), thus suggesting that activity-dependent synaptic mechanisms, rather than series resistance errors cause the decay time prolongation. Together, these data indicate that the increase in input rates increases the transmitter quantity in the cleft which particularly prolongs the $\tau_{\text {slow }}$ through transmitter rebinding.

Studies at the calyx of Held-MNTB principal neuron synapse revealed that in vivo release probability may be approximated in slice recordings by using $1.2 \mathrm{mM} \mathrm{Ca}^{2+}$ in the extracellular solution (Borst, 2010). The dependance of the IPSC decay times on the release probability was shown at other auditory synapses (Balakrishnan et al., 2009; Tang and Lu, 2012). Although the in vivo release probability for the endbulb of Held-SBC synapse remains to be elucidated, we still addressed the question, whether the slow decay of inhibitory currents measured in SBCs is due to an increased release probability in the slice recordings. For this, the weighted decay time constant was measured from the last event within trains consisting of different numbers of pulses and the results were compared for $1.2 \mathrm{mM}$ and $2 \mathrm{mM}$ external calcium concentration (Figure 1F). Single IPSCs and short trains (10 pulses at $100 \mathrm{~Hz}$ ) revealed faster decay time constants under the lower release probability condition. However, with increasing stimulus number and frequency, the weighted decay time constant of the last pulse in the train was similar between the two calcium conditions, (Figure 1F; main effect calcium $p=0.04,1.2$ vs. $2 \mathrm{mM}$ : single, $100 \mathrm{~Hz} 10$ th IPSC $p<0.05$, $100 \mathrm{~Hz}$ 50th IPSC $p=0.72,333 \mathrm{~Hz} 10$ th $p=0.27$ and 50th IPSC $p=0.33, n=11$, RM ANOVA). The slower IPSC at the higher release probability could either be due to transmitter pooling or to multivesicular release. The latter mechanism could explain the data for the single and short IPSC trains. The reduction of extracellular calcium to $1.2 \mathrm{mM}$ decreased the IPSCs amplitudes, especially at the onset of a $100 \mathrm{~Hz}$ train $(50$ pulses) (Figure 1E). However, at the end of the train the baseline IPSC amplitudes were similar to those measured under $2 \mathrm{mM}$ $\left[\mathrm{Ca}^{2+}\right]_{o}$ (IPSC amplitudes $2 \mathrm{mM}$ vs. $1.2 \mathrm{mM}$ : onset $=1$ st IPSC, $p<0.001$; maximum $=$ mean $6-8$ th IPSC vs. mean $10-12$ th IPSC, $p<0.01$; end $=$ mean 48-50th IPSC, $p=0.88, n=6$, RM ANOVA). Thus, the release probability is unlikely to play a role for longer trains of stimuli or high frequency stimulation pointing to transmitter pooling as a mechanism contributing to slow decays.

\section{RECRUITMENT OF FIBERS SLOWS THE IPSC DECAY}

Recruitment of nearby inputs can lead to spillover of transmitter to remote synaptic or extrasynaptic sites, and thereby to intersynaptic pooling. Thus, it is conceivable that the slow IPSC decay in SBCs is caused by ongoing rebinding of transmitter and activation of extrasynaptic receptors, as shown earlier (Balakrishnan et al., 2009; Tang and Lu, 2012). To determine whether synaptic recruitment influences the kinetics of inhibition in SBCs, IPSCs were evoked with increasing stimulus intensities (Figure 2A). The low intensity was set slightly above the threshold with IPSC amplitudes reaching $38.5 \pm 16 \%$ (mean \pm SD, $n=7$ ) of the maximal amplitude evoked by high stimulation intensity. With an increase in stimulus intensity, the amplitude of a single evoked IPSC and the last IPSC in a $100 \mathrm{~Hz}$ train increased threefold (Figure 2B; low vs. high intensity: single, $n=7, p<0.01 ; 100 \mathrm{~Hz} 10$ th IPSC, $n=5, p<0.01$, paired $t$-test). Furthermore, the weighted decay time constants of single and repetitive IPSCs were prolonged at high stimulus intensities (Figure 2C; $\tau_{\mathrm{wd}}$ single: low $=21.6 \pm 0.6 \mathrm{~ms}$, high $=26.3 \pm 0.6 \mathrm{~ms}$, $n=7, p<0.01,100 \mathrm{~Hz}$ 10th IPSC: low $=35.4 \pm 0.8 \mathrm{~ms}$, high $=46.0 \pm 0.8 \mathrm{~ms}, n=5, p<0.01$, paired $t$-tests $)$. On the other hand, the rise time of single IPSCs was not dependent on stimulus intensity, suggesting the recruitment of nearby synaptic inputs (Figure 2D; low $=0.44 \pm 0.03 \mathrm{~ms}$, high $=0.46 \pm 0.03 \mathrm{~ms}$, $n=7, p=0.79$, paired $t$-test). As we neither observed a buildup, nor a run-down of IPSC amplitudes during repetitions at a given stimulus intensity, it is unlikely that the number of activated inputs changed. Therefore, these data suggest that the transmitter quantity substantially contributes to slow inhibitory kinetics. 


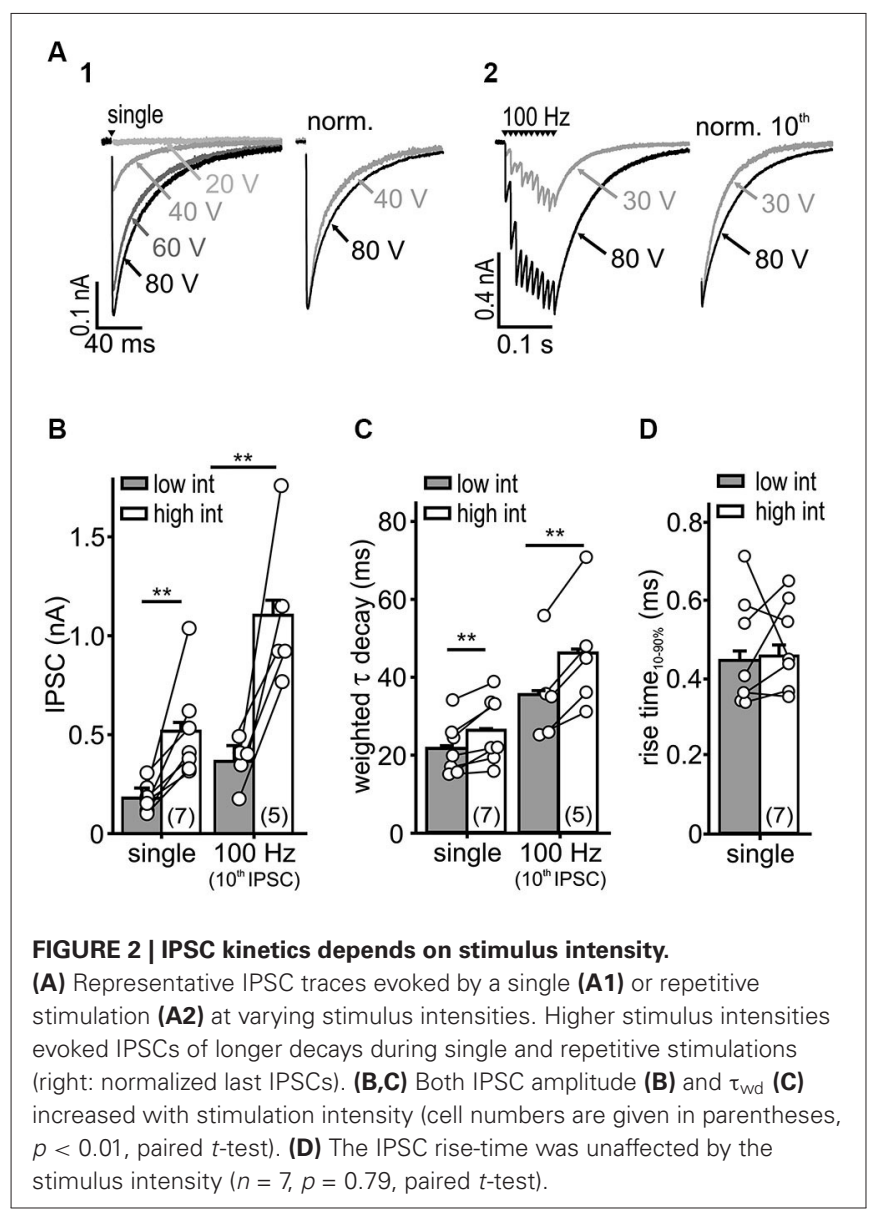

TRANSMITTER UPTAKE CONTRIBUTES TO THE IPSC KINETICS

If transmitter spillover and its clearance from the synaptic cleft shape the IPSC decay in an activity-dependent manner, the postsynaptic currents should be sensitive to a blockade of re-uptake transporters (Otis et al., 1996; Balakrishnan et al., 2009; Tang and Lu, 2012). Bath application of the glycine transporter 2 (GlyT2) inhibitor ORG $25543(20 \mu \mathrm{M}$, Bradaiia et al., 2004; Balakrishnan et al., 2009) slowed down the decay of both single and train IPSCs (Figures 3A,B; $n=6$, RM ANOVA). The fast decay time constant, the respective amplitudes of the exponential components and the IPSC rise time were not affected by the glycine re-uptake block ( $n=6$, control vs. + ORG, $\tau_{\text {fast }}: p=0.15$; $A_{\text {slow }}$ and $\mathrm{A}_{\text {fast }}: p=0.37$, RM ANOVA, rise time: $p=0.99$, paired $t$-test). Therefore, it can be concluded that the $\tau_{\mathrm{wd}}$ prolongation (Figure $3 \mathrm{~B}$ ) is caused by the significantly longer $\tau_{\text {slow }}$ (Figure 3B). Given the similar IPSC decays of the isolated glycinergic and GABAergic single events (Nerlich et al., 2014), the $\tau_{\text {fast }}$ probably describes the intrinsic kinetics of receptor activation and de-activation, whereas the transmitter clearance, relief from saturation and delayed release determine $\tau_{\text {slow. }}$.

In addition to the sensitivity to glycine re-uptake, the IPSC decay phase was also shaped by GABA clearance. Simultaneous inhibition of the respective neuronal- and glial-GABA transporters with $20 \mu \mathrm{M}$ NO 711 (Szabadics et al., 2007; Tang and Lu, 2012) and $100 \mu \mathrm{M}$ SNAP 5114 (Keros and Hablitz, 2005; Song et al., 2013) extended the weighted decay time constant of the last IPSC in $100 \mathrm{~Hz}$ trains. Again, the prolongation of $\tau_{\text {slow }}$ during re-uptake blockade underlie the slowing of train IPSCs (Figures 3C,D; $n=8$, control vs. +NO/SNAP, $\tau_{\text {slow }}$ : $p<0.001, \tau_{\mathrm{wd}}: p<0.01, \mathrm{RM}$ ANOVA). Notably, the GABA uptake is apparently only contributing to the decay during ongoing activity, as single evoked IPSC decays were not affected $(p>$ 0.45) (Figure 3D). Similar to the effects seen after blockade of glycine re-uptake, GABA re-uptake inhibition did not change the fast decay time constants, the respective amplitudes of the exponential components and the IPSC rise times $(n=8$, control vs. $+\mathrm{NO} / \mathrm{SNAP}, \tau_{\text {fast }}: p=0.11, \mathrm{~A}_{\text {slow }}$ and $\mathrm{A}_{\text {fast }}: p=0.43$, RM ANOVA, rise time: $p=0.40$, paired $t$-test). Together, these data suggest that glycine rebinding caused by transmitter pooling due to slow clearance is an important factor in shaping the inhibitory current profile. On the other hand, the GABA re-uptake only contributes at high stimulus input rates to the decay kinetics, when it presumably accumulates in the synaptic cleft.

To investigate transmitter rebinding and the possible contribution of spillover to inhibitory kinetics, we assessed the effects of low affinity GlyR and $\mathrm{GABA}_{\mathrm{A}} \mathrm{R}$ antagonists. The rationale to use weak competitive antagonists to probe for putative remote synapses arises from studies showing that the receptors distant to the release site are likely to encounter a lower transmitter concentration during a synaptic event (Diamond, 2001; Chen and Diamond, 2002). Hence, the low-affinity competitive antagonists are progressively more effective at receptors facing low transmitter concentrations through spillover (Overstreet and Westbrook, 2003; Szabadics et al., 2007; Balakrishnan et al., 2009; Tang and $\mathrm{Lu}, 2012)$. Bath application of a high concentration of SR $95531(200 \mu \mathrm{M})$, employed as a low affinity antagonist of GlyR (Wang and Slaughter, 2005; Beato, 2008; Balakrishnan et al., 2009), reduced the IPSC amplitudes considerably and accelerated the weighted decay time constant of single and repetitive IPSCs (Figures 4A-C; $n=6$, RM ANOVA). Low concentrations of SR $95531\left(10\right.$ and $20 \mu \mathrm{M}$ ) specifically blocked $\mathrm{GABA}_{\mathrm{A}}$ receptors on SBCs and reduced the IPSC amplitudes by $18 \pm 2 \%$ and $16 \pm 3 \%$, respectively (Nerlich et al., 2014). At the concentration of $200 \mu \mathrm{M}$, a $76 \pm 5 \%$ reduction of the IPSC amplitude was observed (Figure 4D; $200 \mu \mathrm{M}$ vs. $10 \mu \mathrm{M}(n=6), p<0.001$; $200 \mu \mathrm{M}(n=6)$ vs. $20 \mu \mathrm{M}(n=11), p<0.001$, ANOVA $)$. This result is consistent with an additional antagonistic action of a high SR 95531 concentration at GlyR, as opposed to specific $\mathrm{GABA}_{\mathrm{A}} \mathrm{R}$ blockade at concentrations of 10 and $20 \mu \mathrm{M}$ (Nerlich et al., 2014). To further confirm the competitive antagonistic action of SR 95531 at GlyR, the glycine concentration in the cleft was increased by co-applying the glycine re-uptake inhibitor ORG 25543. This partially reversed the long $\tau_{\mathrm{wd}}$ confirming that the current decay is regulated by the amount of available glycine (Figure 4D; change of $\tau_{\mathrm{wd}}:+20 \mu \mathrm{M} \mathrm{SR}=-8.1 \pm 2.4 \%, n=13 ;+200 \mu \mathrm{M}$ $\mathrm{SR}=-35.3 \pm 2.5 \%, n=6 ;+200 \mu \mathrm{M} \mathrm{SR}+\mathrm{ORG}=-21.2 \pm 5.5 \%$, $n=6 ; 20 \mu \mathrm{M}$ vs. $200 \mu \mathrm{M}$ SR $p<0.001,200 \mu \mathrm{M}$ SR vs. $200 \mu \mathrm{M}$ $\mathrm{SR}+\mathrm{ORG} p=0.01$, ANOVA). As the uptake blockers reveal transmitter spillover by increasing its quantity and enabling distant 
A

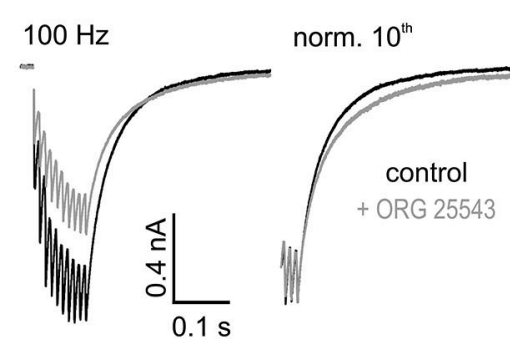

C

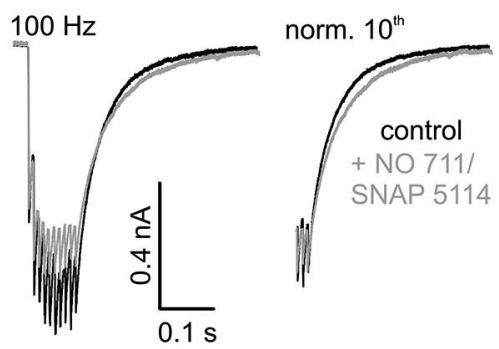

B

1

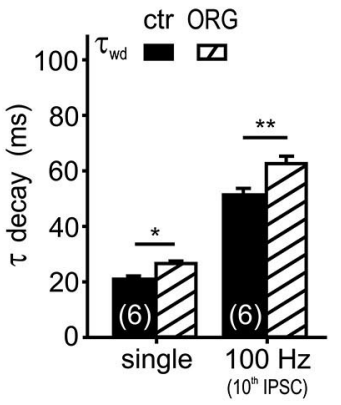

D

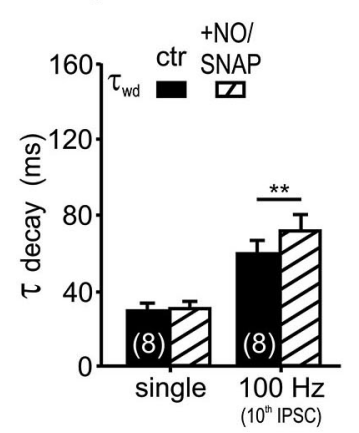

2

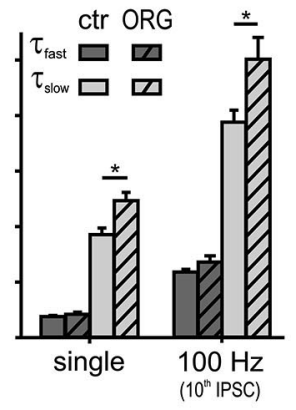

2

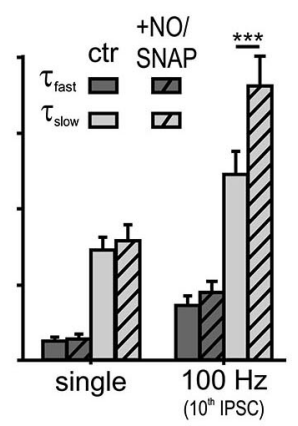

FIGURE 3 | Glycine and GABA re-uptake contributes to the IPSC kinetics. (A) Average traces of $100 \mathrm{~Hz}$ IPSC trains, before and after the bath application of the GlyT2 blocker ORG $25543(20 \mu \mathrm{M})$. The weighted time constant increased under the glycine re-uptake block (right: traces normalized to the last IPSC). (B) Inhibition of GlyT2 prolonged the $\tau_{w d}$ (B1) upon single $(p<0.05)$ and repetitive $(p<0.01)$ synaptic stimulation due to an increase in $\tau_{\text {slow }}(p<0.05)$. The fast exponential component was unaffected (B2) $(n=6$, $p=0.15$, RM ANOVA). (C) IPSCs evoked at $100 \mathrm{~Hz}$, before and after the bath application of $20 \mu \mathrm{M}$ NO 711 and $100 \mu \mathrm{M}$ SNAP 5114. The weighted decay time constant increased under the GABA re-uptake block (right: traces normalized to the last IPSC). (D) Inhibition of GABA uptake prolonged the weighted decay of IPSCs at $100 \mathrm{~Hz}(p<0.01)$ (D1) by increasing $\tau_{\text {slow }}$ $(p<0.001)$ (D2). The IPSC kinetics of single events were not affected ( $p>$ $0.45, n=8$, RM ANOVA). receptors to encounter a lower concentration of an agonist (Chen and Diamond, 2002; Thomas et al., 2011), our data showing a decay time prolongation under ORG 25543 are consistent with glycine spillover.

Inhibitory currents in SBCs show an activity-dependent depression of the IPSC peak amplitudes ( $\mathrm{I}_{\text {peak }}$, Figure 4E). Yet, under the low affinity GlyR antagonist (200 $\mu \mathrm{M}$ SR 95531), the peak amplitudes showed a weaker depression which in some cells even changed into facilitation (Figures $4 \mathrm{E}, \mathrm{F}$ ). This result is consistent with a relief from receptor saturation and/or desensitization (Chanda and Xu-Friedman, 2010). Thus, the peak IPSC depression at high input rates is presumably caused by postsynaptic receptor saturation and/or desensitization, rather than presynaptic short-term plasticity.

Contrary to glycine signaling, GABA is apparently not activating nearby synapses. Even at high stimulation rates, the low affinity $\mathrm{GABA}_{\mathrm{A}} \mathrm{R}$ antagonist TPMPA (Szabadics et al., 2007; Tang and $\mathrm{Lu}, 2012$ ) neither affected the IPSC decay nor the amplitudes, suggesting that the postsynaptic $\mathrm{GABA}_{\mathrm{A}} \mathrm{R}$ could be tightly coupled to release sites of the transmitter and, thus, encounter consistently high GABA concentration (Figures 4G-I; control vs. TPMPA $\tau_{\mathrm{wd}}$ : single $p=0.97 ; 100 \mathrm{~Hz}$ 10th IPSC $p=0.62$; IPSC amplitude: single $p=0.67 ; 100 \mathrm{~Hz} 10$ th IPSC $p=0.19 ; n=8$, RM ANOVA). In summary, the apparently low uptake capacity of glycine and GABA transporters slows the decay of IPSCs, thereby enabling spillover of glycine. While we found no evidence for spillover of GABA, the transmitter quantity and intrinsic receptor properties probably account for the slow GABAergic transmission.

\section{ACTIVITY-DEPENDENT ASYNCHRONOUS RELEASE}

A further mechanism putatively contributing to IPSC decay time in SBCs could be an activity-induced desynchronization of vesicle release, as shown for several inhibitory synapses (Lu and Trussell, 2000; Hefft and Jonas, 2005; Tang and Lu, 2012). To test this hypothesis, high frequency stimulation (100 and $333 \mathrm{~Hz}$ ) of inhibitory inputs to SBCs was employed to evoke small asynchronous events in the decay phase following the IPSC trains (Figure 5A). The quantity of asynchronous IPSCs increased with stimulus duration (Figures 5B,E) and frequency (Figures 5C,F). To compare the spontaneously occurring IPSCs (sIPSC, without input stimulation) and delayed IPSCs following repetitive input stimulation, the events were detected during $1 \mathrm{~s}$ before synaptic stimulation and $2 \mathrm{~s}$ after the last evoked IPSC 
A

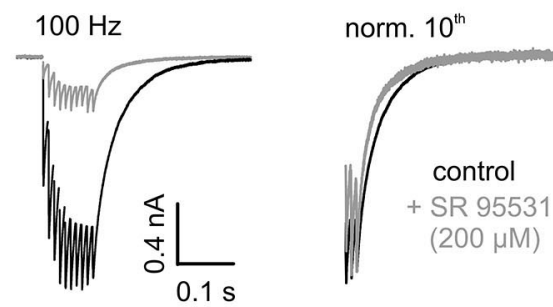

D

1

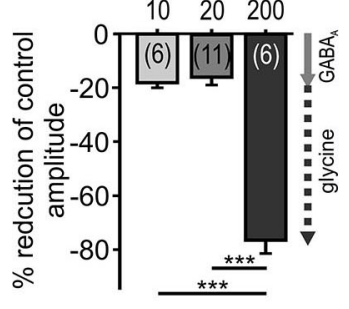

G

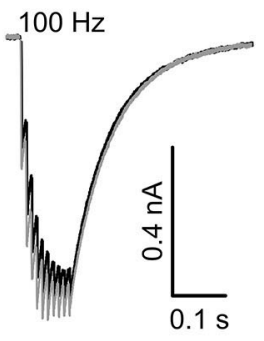

B

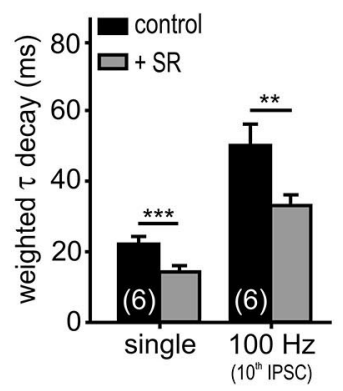

E

2
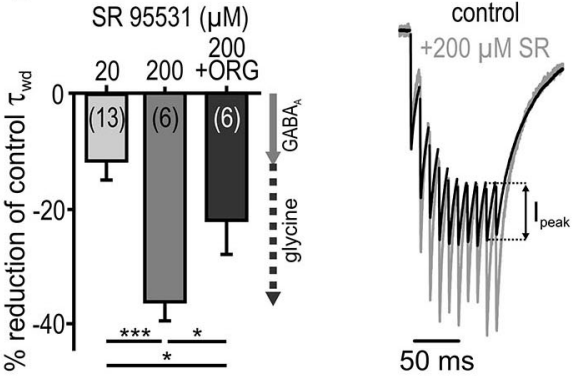

C

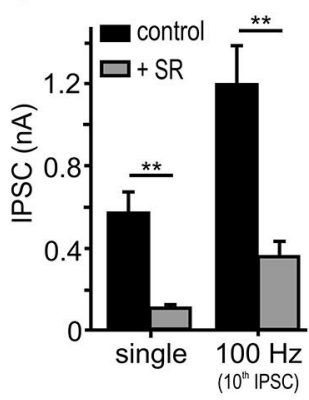

$\mathbf{F}$

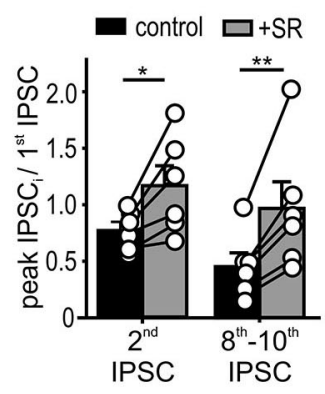

I

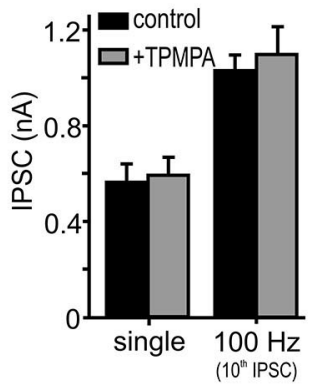

FIGURE 4 | Low affinity antagonist reveals spillover and rebinding of glycine. (A) Responses to 10 stimuli at $100 \mathrm{~Hz}$, under the control condition and in the presence of a weak glycine receptor antagonist SR $95531(200 \mu \mathrm{M})$. The weighted decay decreased under SR 95531 (right: traces normalized to the last IPSC). (B,C) Summary data showing faster IPSC decay time constants (B) and substantially reduced amplitudes (C) under the weak antagonism of SR95531 for single and $100 \mathrm{~Hz}$ stimulation ( $n=6$, RM ANOVA). (D) Percentage reduction of amplitudes (D1) and decay values (D2) of single IPSCs under different SR 95531 concentrations and SR 95531+ ORG 25543 compared to control condition (100\%). At concentrations of $10 \mu \mathrm{M}$ and $20 \mu \mathrm{M}$, SR 95531 had similar inhibitory effects on IPSC amplitude, due to a specific $G A B A_{A} R$ antagonism (Nerlich et al., 2014) (gray arrow $=G_{A B A}$ receptor contribution). At a concentration of $200 \mu \mathrm{M}$, SR 95531 further reduced the amplitude and accelerated the IPSCs decay time. The faster IPSCs under $200 \mu \mathrm{M}$ SR 95531, were again prolonged after the additional inhibition of GlyT2 by
$\mathrm{H}$

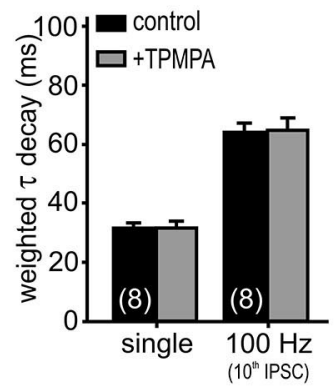

ORG $25543(20 \mu \mathrm{M})$ (D2) suggesting a low-affinity inhibition of glycine receptors by $200 \mu \mathrm{M}$ SR 95531 (dashed arrow = putative glycine receptor blockade). Cell numbers are given in parentheses; ANOVA. (E) Representative traces (10 IPSCs at $100 \mathrm{~Hz}$ ) for control condition and superfusion of $200 \mu \mathrm{M}$ SR 95531 normalized to the

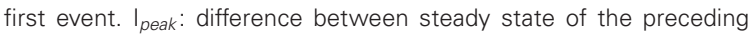
event and peak of the successive event. (F) The peak amplitude of the second IPSC and the mean of the 8th-10th peak IPSCs relative to the first IPSC increased in the presence of SR 95531 (2nd/1st IPSC ratio increased by $0.46 \pm 0.12, p<0.05$; 8 th-10th/1st IPSC ratio increased by $0.96 \pm 0.23, p<0.01$, paired $t$-test, symbols: single cell data, bars: mean \pm SEM). The low affinity antagonism of

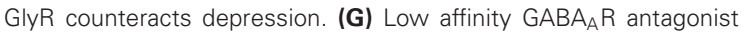
(200 $\mu$ M TPMPA) had no effect on IPSCs (normalized to the 10th IPSC: right). (H,I) Summary data showing a lack of TPMPA effect on the IPSC decays (single: $p=0.96,100 \mathrm{~Hz}: p=0.62$ ) and the amplitudes (single: $p=0.66,100 \mathrm{~Hz}: p=0.19, n=8$, RM ANOVA). ${ }^{*} p<0.05,{ }^{*} p<0.01,{ }^{*}{ }^{*} p<0.001$. (see methods). The number of asynchronous events increased significantly after the $333 \mathrm{~Hz}$ stimulation (Figure 5E summary data for 4 cells and respective presentation of 10, 25 and 50 stimuli at $333 \mathrm{~Hz} z$ values $>10.1, p<0.001, z$-test), compared to the rate of sIPSC before stimulation (Figure 5D; mean \# of sIPSCs $/ 20 \mathrm{~ms}$ bin $=0.56 \pm 0.08, n=4)$. This result suggests 


\section{A}

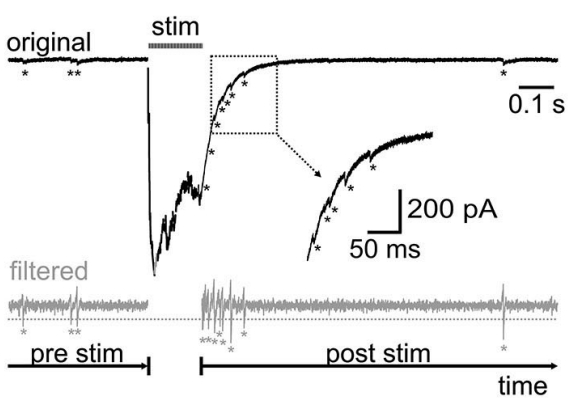

B

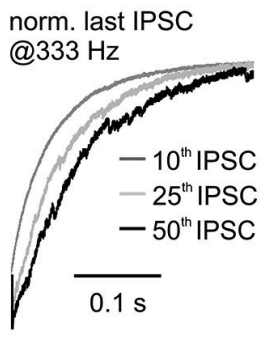

C

norm. $50^{\text {th }}$ IPSCs

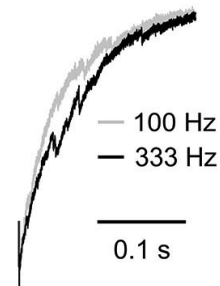

D

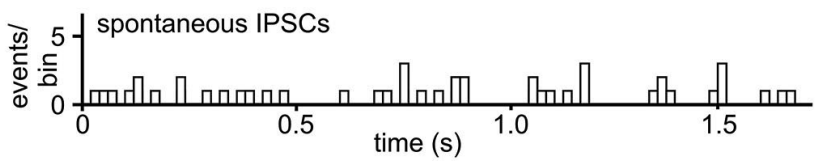

E

1

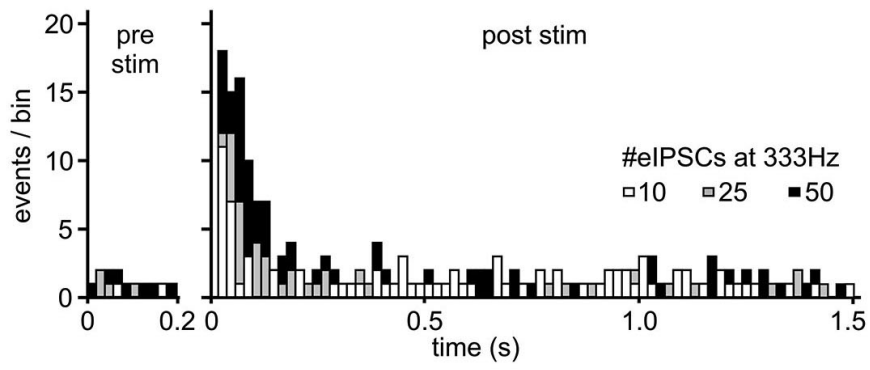

$\mathbf{F}$

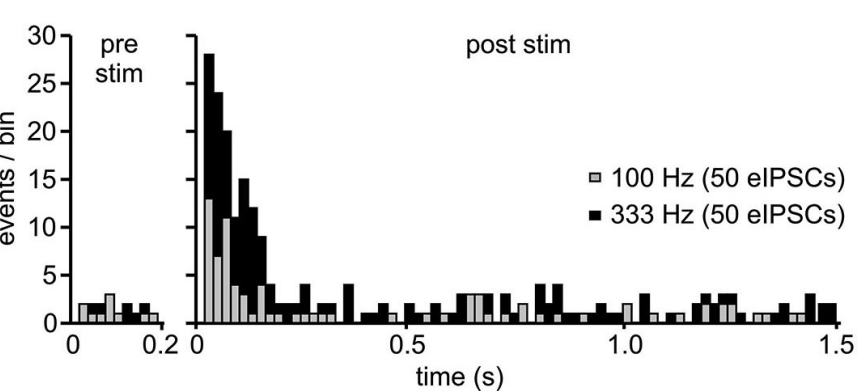

2

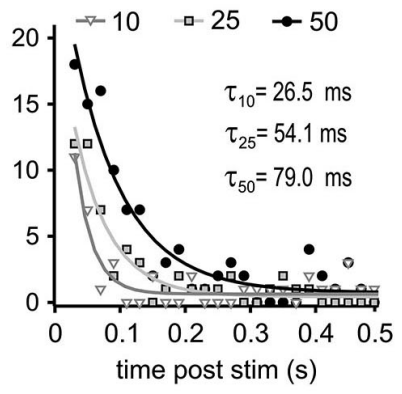

2

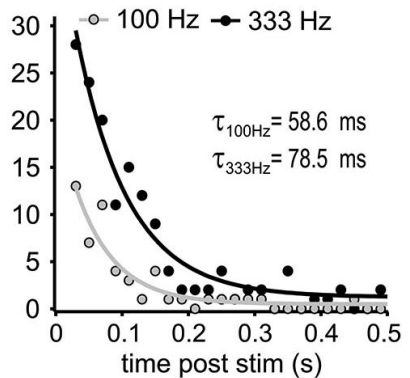

FIGURE 5 | Activity-dependence of asynchronous release. (A)

Representative trace with detected asynchronous release events, before and after 50 stimuli at $333 \mathrm{~Hz}$ (upper panel). For event detection the signal was bandpass filtered between 50 and $1500 \mathrm{~Hz}$ (bottom panel). Potential events were detected when the filtered current amplitude exceeded 1.96 times $(p<0.05)$ the standard deviation of the noise (dashed gray line). Note the increased incidence of events in the decay phase of the last IPSC. (B) Normalized last IPSCs elicited by different numbers of stimuli in a $333 \mathrm{~Hz}$ train. (C) Superimposed normalized last IPSCs in a 50-pulse train at $100 \mathrm{~Hz}$ and $333 \mathrm{~Hz}$. (D) Histogram of spontaneous IPSCs before synaptic stimulation of inhibitory inputs ( $n=4$ cells, bin width: $20 \mathrm{~ms}$ ). (E1) Histograms of asynchronous release events before ( = spontaneous events, pre stim) and after the $333 \mathrm{~Hz}$ input stimulation ( = asynchronous and spontaneous events, post stim) with different number of stimuli ( $n=4$ cells, bin width: $20 \mathrm{~ms}$, post stim $t=0$ refers to the time of the last IPSC in the train). Following synaptic stimulation, the time course of asynchronous events relaxed back to the resting state with a mono-exponential function. The increase of asynchronous events during the decay phase depends on the presynaptic activity. (E2) Mono-exponential fits to the data from (E1). The initial incidence of events, and the time constant $(\tau)$ depend on stimulus number ( 10 vs. 25 vs. 50 stimuli $p<0.05$ for each comparison). (F) Input frequency determines the amount of asynchronous release. (F1) Summary histograms of asynchronous events from 6 cells, before and after 50-pulse stimulation at $100 \mathrm{~Hz}$ and $333 \mathrm{~Hz}$. (F2) Mono-exponential fits to the data from F1. The initial incidence of events was increased and the exponential time constant prolonged with higher input frequency $(100 \mathrm{~Hz}$ vs. $333 \mathrm{~Hz} \mathrm{p}<0.05)$. the occurrence of activity induced asynchronous events in the decay phase of IPSC trains. Detailed analyses revealed the time course of incidence of asynchronous events which was best fit with a mono-exponential function relaxing back to the resting 
state. The following parameters were used to quantify the delayed release: initial amplitude (peak incidence of asynchronous events (A), an exponential time constant $(\tau)$ and a steady state value (c) (Figure 5E; fit comparison 10 vs. 25 vs. 50 stimuli $p<0.001$, F-test). The peak incidence of asynchronous events after stimulation at $333 \mathrm{~Hz}$ increased almost 2-fold by extending the train from 10 to 50 pulses ( $A_{\# \text { \#IPSC }} 95 \%$ CI [lower, upper]: $A_{10}=10.6$ $[9.1,12.2]$ events, $A_{25}=12.9[11.7,14.0]$ events, $A_{50}=18.8$ $[17.3,20.3]$ events, 10 vs. 25 vs. 50 stimuli $p<0.05)$. The exponential time constant was also prolonged ( $\tau_{\text {\#eIPSC }} 95 \% \mathrm{CI}$ [lower, upper]: $\tau_{10}=26.5[20.5,37.4] \mathrm{ms}, \tau_{25}=54.1$ [46.8, $64.4] \mathrm{ms}, \tau_{50}=79.0[69.7,91.1] \mathrm{ms}, 10$ vs. 25 vs. 50 stimuli $p<0.05)$, whereas the steady state values were similar to the mean sIPSC levels $1 \mathrm{~s}$ before stimulation (c\#eIPSC 95\% CI [lower, upper]: $c_{10}=0.63[0.52,0.75]$ events/bin, $c_{25}=0.43[0.33,0.53]$ events/bin, $c_{50}=0.73[0.59,0.87]$ events/bin; sIPSCs \pm SEM: prior to 10 eIPSCs $=0.54 \pm 0.12$ sIPSCs/bin, prior to $25 \mathrm{eIP}$ $\mathrm{SCs}=0.48 \pm 0.10 \mathrm{sIPSCs} / \mathrm{bin}$, prior to $50 \mathrm{eIPSCs}=0.74 \pm 0.10$ sIPSCs/bin, $p>0.05$ ).

The rate of delayed release was not only dependent on the stimulus duration, but also on the stimulation frequency (Figure 5C,F summary data for 6 cells). Figure 5F, shows that presynaptic activity determines the quantity and duration of asynchronous release (A or $\tau, 95 \%$ CI [lower, upper]: $A_{100 H z}=12.4$ $[10.8,13.9]$ events, $A_{333 \mathrm{~Hz}}=28.3[26.0,30.5]$ events, $p<0.05$; $\tau_{100 \mathrm{~Hz}}=58.6[48.3,74.7] \mathrm{ms}, \tau_{333 \mathrm{~Hz}}=78.5[69.3,90.7] \mathrm{ms}$, $p<0.05, n=6$, fit comparison $100 \mathrm{~Hz}$ vs. $333 \mathrm{~Hz} p<0.001$, F-test).

The putative cause for the delayed asynchronous transmitter release is the accumulation of presynaptic calcium during high frequency IPSC trains. This can be experimentally enhanced by replacing the extracellular calcium with strontium, or alternatively, the effect can be reduced by applying a cell permeable calcium chelator that accelerates the decay of presynaptic calcium transients (Goda and Stevens, 1994; Atluri and Regehr, 1996, 1998; Lu and Trussell, 2000; Xu-Friedman and Regehr, 2000; Hefft and Jonas, 2005; Best and Regehr, 2009; Tang and Lu, 2012). To test whether the delayed asynchronous events can prolong the IPSCs decay times, their incidence was increased by replacing $2 \mathrm{mM}$ extracellular calcium by $8 \mathrm{mM}$ strontium (Figures 6AC). In addition to a higher frequency of asynchronous events (A) shortly after the $100 \mathrm{~Hz}$ stimulation (10 eIPSCs), strontium also caused a prolongation of the time course $(\tau)$ of the last IPSC (Figures 6B,C; $n=6$, mono-exponential fit comparison: $p<0.001, F$-Test; A or $\tau 95 \%$ CI [lower, upper]: $\mathrm{A}_{\mathrm{Ca}^{2+}}=6.8$ $[5.7,7.9]$ events, $A_{\mathrm{Sr}^{2+}}=21.2[19.4,23.0]$ events; $\tau_{\mathrm{Ca}^{2+}}=13.5$ $[9.4,23.9] \mathrm{ms}, \tau_{\mathrm{Sr}^{2+}}=47.2[40.9,55.8] \mathrm{ms}, \mathrm{Ca}^{2+}$ vs. $\mathrm{Sr}^{2+}$ $p<0.05)$. Consistent with the observation that asynchronous release strongly depends on synaptic activity (Figure 5), $8 \mathrm{mM}$ strontium was more potent in prolonging the IPSC $\tau_{\mathrm{wd}}$ following higher stimulation rate and longer stimulation (Figure $6 \mathrm{C} ; \mathrm{Ca}^{2+}$ vs. $\mathrm{Sr}^{2+} 100 \mathrm{~Hz} 10$ th $p<0.05 ; 333 \mathrm{~Hz} 50$ th $p<0.01, n=6$, RM ANOVA). Notably, single IPSC decays were not affected by the $\mathrm{Ca}^{2+}$ replacement $(p=0.8)$. These results suggest that the slow decay of IPSCs is indeed shaped by the asynchronous release which in turn is determined by the rate of presynaptic activity.
To further address this issue, the contribution of the delayed vesicle release to IPSC decay times was determined through reduction of presynaptic calcium with the calcium chelator EGTAAM $(100 \mu \mathrm{M})$ (Figures 6D-G). The IPSC amplitudes strongly decreased under EGTA-AM by $55 \pm 8 \%$ for single IPSC, $71 \pm 4 \%$ for the 10th IPSC at $100 \mathrm{~Hz}$ and $55 \pm 10 \%$ for 50th IPSC at $333 \mathrm{~Hz}$, presumably due to a reduction in the peak $\mathrm{Ca}^{2+}$ concentration in the presynaptic terminal (Atluri and Regehr, 1996). The significant increase of asynchronous events observed in control condition after $333 \mathrm{~Hz}$ stimulation (50 IPSCs) vanished completely under EGTA-AM (Figure 6E; change of asynchronous events after stimulation compared to baseline level before stimulation: control $z=29.2, p<0.001$; +EGTA-AM $z=-1.01$, $p=0.16, z$-test). Moreover, the weighted decay time constant was shortened by $30 \pm 3 \%$ regardless of stimulus condition (Figure 6F; EGTA-AM effect vs. frequency $p=0.9, n=5$, RM ANOVA) and transmitter type (glycine, GABA or both) (Figure 6G; EGTA-AM effect vs. transmission type $p=0.59$, $n=5$ for each condition, ANOVA). Together, these data suggest that both glycine and GABA contribute to the delayed release and thereby shape the inhibitory current profile in an activitydependent manner.

\section{DISCUSSION}

The mixed glycine-GABA transmission observed in SBCs is for the most part dominated by glycine but it still exhibits slow synaptic decays resulting in a long lasting, tonic-like inhibition. While glycine primarily contributes to the IPSC amplitudes, GABA enhances and prolongs the total inhibitory conductance, especially at higher firing rates (Nerlich et al., 2014). Here we demonstrate that the resulting IPSC decay strongly depends on both the synaptic activity and the number of recruited inhibitory fibers, each increasing the amount of transmitters released. The slow glycine and GABA clearance permits a longer availability of the transmitters in the synaptic cleft, thereby enabling transmitter rebinding and glycine spillover. Moreover, the IPSC kinetics is dynamically shaped by the delayed release of glycine and GABA. In addition to the shift towards slower GABAergic transmission at higher input rates (Nerlich et al., 2014), these activity-dependent mechanisms jointly determine the remarkably slow inhibition in SBCs.

\section{TRANSMITTER REBINDING AND SPILLOVER CONTRIBUTE TO THE IPSC DECAY}

The SBCs of the cochlear nucleus are the first synaptic center where primary auditory input from the cochlea is integrated with a higher-order, acoustically-evoked inhibition to preserve or improve temporal precision on the sub-millisecond scale (Gai and Carney, 2008; Dehmel et al., 2010; Kuenzel et al., 2011). Such synaptic inhibition is likely to contribute to the temporal synchronization of AP discharges to a particular phase of a low frequency tone burst (Joris et al., 1994; Paolini et al., 2001; Dehmel et al., 2010). Saying this, it should not be disregarded that also other previously discussed mechanisms (Nerlich et al., 2014), such as coincidence of presynaptic inputs also add to the synchronicity of postsynaptic SBC discharges (Kuhlmann et al., 2002; Xu-Friedman and Regehr, 2005). With 
A

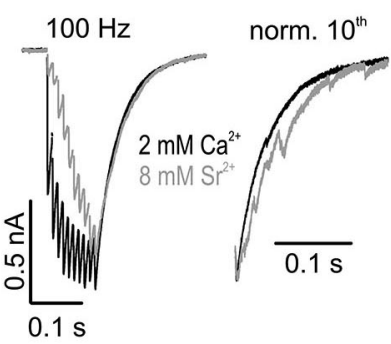

D

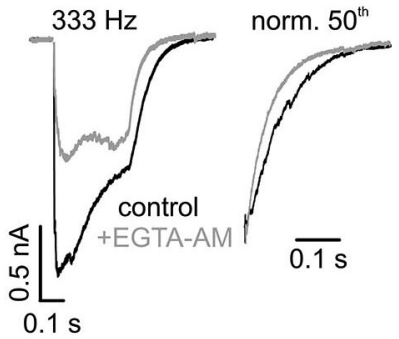

B

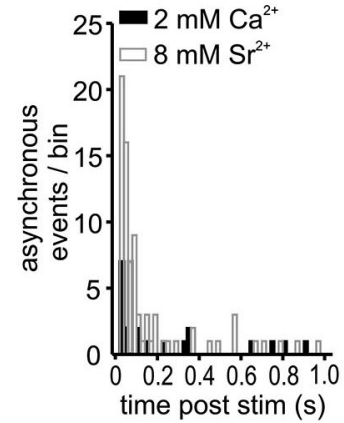

E

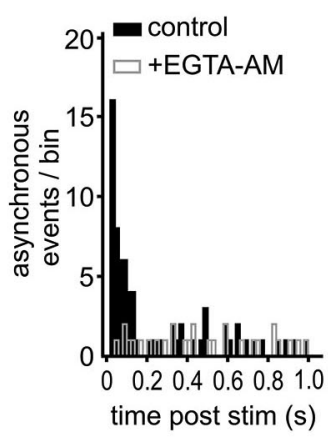

2

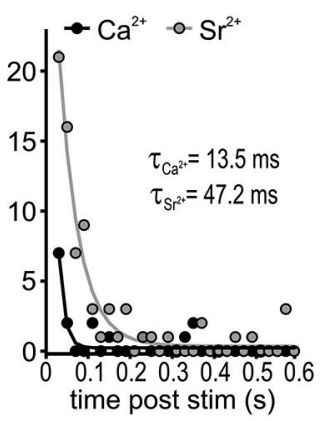

$\mathbf{F}$

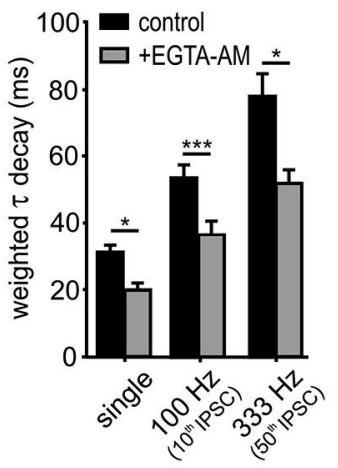

C

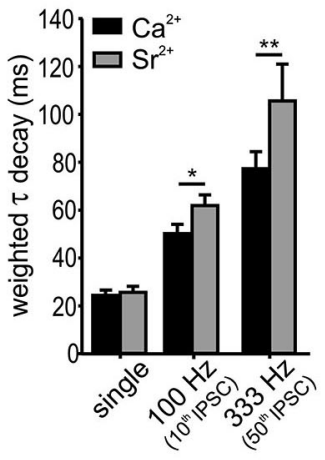

G

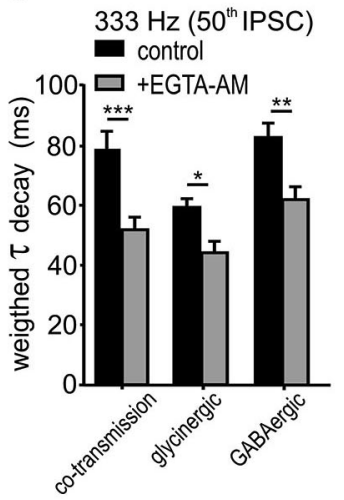

FIGURE 6 | Asynchronous release influences IPSC decay in SBCs. (A) Superimposed responses to a $100 \mathrm{~Hz}$ stimulation in $2 \mathrm{mM}$ calciumand $8 \mathrm{mM}$ strontium-ACSF. Right: Normalized last IPSCs showing an increased incidence of asynchronous release events under strontium. (B1) Summary histograms of asynchronous release events, before and after a 10 pulse stimulation at $100 \mathrm{~Hz}$ for both conditions $(n=6)$. (B2) Mono-exponential fits to the data in B1. The amount of asynchronous events after stimulation was increased and the time of increased incidence prolonged under $8 \mathrm{mM} \mathrm{Sr}^{2+}$ ( $\mathrm{A}$ and $\tau$ : $\mathrm{Ca}^{2+}$ vs. $\mathrm{Sr}^{2+} p<0.05$ ).

(C) Substitution of $\mathrm{Ca}^{2+}$ by $\mathrm{Sr}^{2+}$ prolonged the weighted decay time of IPSCs after $100 \mathrm{~Hz}$ and $333 \mathrm{~Hz}$ stimulation, but not of single IPSCs $(n=6$, single: $p=0.8,100 \mathrm{~Hz}: p<0.05,333 \mathrm{~Hz}: p<0.01$, RM ANOVA).
(D) Averaged trains of 50 IPSCs at $333 \mathrm{~Hz}$ before and after bath application of $100 \mu \mathrm{M}$ EGTA-AM. Right: normalized last IPSCs. (E) Summary histograms of asynchronous release events before and after application of EGTA-AM. Note the lack of the increase in asynchronous release after stimulation in EGTA-AM ( $n=5$, bin width: $20 \mathrm{~ms}$; control: $z=29.2 p<0.001 ;+$ EGTA-AM: $z=-1.01 p=0.16, z$-test). (F) EGTA-AM shortened $\tau_{w d}$ by about $30 \%$ regardless of stimulation frequency $(n=5$, ${ }^{*} p<0.05,{ }^{* *} p<0.001$, RM ANOVA). (G) EGTA-AM equally affects the control (mixed glycine/GABA) IPSCs, isolated glycinergic (+20 $\mu \mathrm{M} \mathrm{SR}$ 95531), and GABAergic IPSCs (+0.5 $\mu \mathrm{M}$ strychnine) in terms of decreasing the weighted decay time constants (co-transmission: $n=5, p<0.001$; glycinergic: $n=5, p<0.05$; GABAergic: $n=5, p<0.01$; ANOVA). respect to the inhibitory effects, it was shown that an activitydependent regulation of inhibitory strength mediated trough a slow glycine-GABA transmission adjusts the fidelity at the endbulb of Held synapse towards fast rising and large EPSPs (Kuenzel et al., 2011; Xie and Manis, 2013; Nerlich et al., 2014). The present data further demonstrate that the inhibitory strength crucially depends on the presynaptic firing rate, which is of particular physiological importance given the weak inhibition at lower sound intensities, i.e., low firing rates (Kuenzel et al., 2011). Following strong inhibitory stimulation, slow glycine and GABA clearance from the synaptic cleft appears to enable ongoing rebinding of transmitters and intersynaptic pooling of glycine. A similar mechanism was previously shown to mediate prolonged inhibition of granule cells in the rat DCN (Balakrishnan et al., 2009) and of the nucleus laminaris neurons in the chick auditory brainstem (Tang and Lu,
2012). Several lines of evidence suggest that both the GlyT2 and the GABA transporters GAT1/3 contribute to the kinetics of activity-dependent inhibition at SBCs. Particularly, the slow decay phase $\left(\tau_{\text {slow }}\right)$ was affected by increasing stimulus frequencies, suggesting longer availability of transmitters. Similar $\tau_{\text {slow }}$ prolongation was also observed in the presence of glycine and GABA transporter antagonists. As the respective slowly decaying current is most likely due to slow transmitter clearance (Otis et al., 1996; Williams et al., 1998), our data are consistent with transporter saturation during higher neuronal activity. In line with this, the vesicular inhibitory amino acid transporter (VGAT), which depends on the supply of cytosolic transmitter to enable synaptic corelease of glycine and GABA (Wojcik et al., 2006), is apparently not the rate limiting factor for efficient refilling of inhibitory vesicles (Apostolides and Trussell, 2013). 
At mixed glycine-GABA synapses, several factors determine the characteristics of the postsynaptic response: (i) the glycine/GABA ratio in synaptic vesicles which is not only determined by the higher VGAT affinity for glycine than for GABA (McIntire et al., 1997; Bedet et al., 2000); but also crucially depends on the availability of glycine through GlyT2 activity (Rousseau et al., 2008); and (ii) the postsynaptic receptor expression levels, clustering, and localizations (Todd et al., 1996; Dugué et al., 2005). In our recent study, we described a relative increase of the GABAergic component from 5 to $12 \%$ of the mixed IPSC amplitude during ongoing synaptic activity (Nerlich et al., 2014). When glycine and GABA were puff-applied (equimolar concentrations of $500 \mu \mathrm{M}$ ), the current amplitude ratio was $\sim 3: 2(1.7: 1.2 \mathrm{nA})$, indicating that $\mathrm{GABA}_{\mathrm{A}} \mathrm{R}$ availability is probably not the rate limiting factor for restricted GABAergic contribution to the IPSC. Presently, we found no evidence for GABA spillover to distant receptors that could account for the activity-dependent increase in the GABAergic proportion. Thus, the slow glycine clearance by GlyT2 and its low intracellular availability may possibly explain the progressively higher GABAergic signaling at in vivo-like firing rates.

Compared to the events elicited in $1.2 \mathrm{mM}\left[\mathrm{Ca}^{2+}\right]_{o}$, IPSCs measured under the standard $2 \mathrm{mM}\left[\mathrm{Ca}^{2+}\right]_{o}$ condition were found to be slower after shorter stimulus trains or at lower input rates, possibly indicating a contribution of multivesicular release. However, longer or high frequency stimulation (50 pulses at $100 \mathrm{~Hz}, 10$ or 50 pulses at $333 \mathrm{~Hz}$ ) evoked IPSC of comparable amplitudes towards the end of the train and the similar decay kinetics of the last event. This suggests that prolonged neuronal activity at physiological-like rates leads to a steady state transmitter level in the cleft, independent of the initial release probability. The data also argue against the prominent receptor desensitization, because its effect would render IPSCs faster with increasing transmitter concentrations at higher rates (Jones and Westbrook, 1996), which was not observed in our experiments.

Glycine receptor saturation and spillover onto nearby or distant receptors probably shapes the IPSC kinetics at physiologically relevant firing rates. Due to the lack of effect of the low-affinity $\mathrm{GABA}_{\mathrm{A}}$ antagonist, we conclude that the respective receptors are probably tightly coupled to the release sites and unlikely to saturate. In line with this notion, is the lack of $\mathrm{GABA}_{\mathrm{A}} \alpha 6$ and $\delta$ subunit expression on SBCs (Campos et al., 2001) which were shown to constitute the extrasynaptic receptors (Nusser et al., 1998; Kullmann et al., 2005). The slow IPSC kinetics measured at SBCs contrast with respective data for other inhibitory auditory synapses with decay time constants $<5 \mathrm{~ms}$, in which GABA is either not engaged or plays a minor role in determining the response decay time (Awatramani et al., 2004; Magnusson et al., 2005; Chirila et al., 2007; Couchman et al., 2010). As the SBC IPSCs progressively resembled the kinetics of pharmacologically isolated GABAergic events at increasing input frequencies, the mechanisms engaged with GABA release are likely to regulate the duration of inhibition at physiologically relevant rates (Nerlich et al., 2014). One possible contributing mechanism, though not a focus of the present study, is the kinetics of the $\mathrm{GABA}_{\mathrm{A}}$ receptor itself. The $\alpha 3$ subunit, linked to slow kinetics, deactivationand desensitization rates (Verdoorn, 1994; Gingrich et al., 1995) is coexpressed with the subunits $\alpha 1, \alpha 5, \beta 3$ and $\gamma 2 \mathrm{~L}$ in the rat AVCN (Campos et al., 2001). In olfactory bulb neurons of juvenile rats, the deactivation kinetics of GABA-evoked mIPSCs can span a $\tau_{\mathrm{wd}}$ range of 3-30 $\mathrm{ms}$ through the expression of different compositions of the fast $\alpha 1$ and the slow $\alpha 3$ subunits in the receptor heteromers (Eyre et al., 2012). Therefore, it is conceivable that the specific composition of $\mathrm{GABA}_{\mathrm{A}}$ subunits in SBCs partially contributes to an increase in $\tau_{w d}$ which ranged between $20-90 \mathrm{~ms}$ in an activity-dependent manner. Notably, even the isolated glycinergic spontaneous- and evoked-IPSCs exhibit slow synaptic decays (Xie and Manis, 2013, 2014; Nerlich et al., 2014). This may be surprising, given the general developmental down-regulation of the GlyR $\alpha 2$ subunit, associated with slower receptor kinetics (Veruki et al., 2007) in the cochlear nucleus and in the superior olivary compex (Sato et al., 1995; Friauf et al., 1997). However, the developmental replacement by the $\alpha 1$ subunit in the AVCN seems in the AVCN, as low levels of $\alpha 2$ mRNA were found up to the third postnatal week (Piechotta et al., 2001). Our data substantiate the hypothesis of a persistent $\alpha 2$ subunit expression throughout adulthood by showing that single pulse stimulation evokes IPSCs of similar $\tau_{\mathrm{wd}}$ for pharmacologically isolated glycinergic, GABAergic, and mixed glycine-GABA events (Nerlich et al., 2014). Here, further corroboration is provided by showing comparable slow kinetics of the spontaneous IPSCs and IPSCs synaptically elicited in low release probability conditions. In both cases, the amount of released transmitters is presumed low, thus reducing the contribution of activity-dependent mechanisms. Although our results argue for a role of slow GlyR and $\mathrm{GABA}_{\mathrm{A}} \mathrm{R}$, this still seems to be only an additional mechanism shaping the overall kinetic profile.

\section{INHIBITORY KINETICS IS SHAPED BY THE ACTIVITY-INDUCED DELAYED RELEASE}

Asynchronous (or delayed) transmitter release is another mechanism to generate a long-long lasting inhibition in the brain (Lu and Trussell, 2000; Hefft and Jonas, 2005; Tang and $\mathrm{Lu}, 2012)$. The ongoing synaptic activity can lead to $\mathrm{Ca}^{2+}$ accumulation in the presynaptic terminal, thereby causing the loss of coupling between the presynaptic AP and the release machinery (Chen and Regehr, 1999). Our data from the present and previous study (Nerlich et al., 2014) consistently show the activity-dependent change of release mode. The individual IPSCs were clearly segregated at $100 \mathrm{~Hz}$, indicating synchronized quantal release, whereas the $333 \mathrm{~Hz}$ stimulation evoked a large plateau current caused by asynchronous release. Notably, the delayed asynchronous release events, mediated by both glycine and GABA, were observed at both frequencies during the decay phase of the last IPSC. The prominent effect of the slow calcium chelator EGTA-AM in our experiments, suggests a loose coupling between presynaptic $\mathrm{Ca}^{2+}$ channels and the $\mathrm{Ca}^{2+}$ sensor, possibly in a form of microdomains (Meinrenken et al., 2002; Eggermann et al., 2012; Vyleta and Jonas, 2014). The $\mathrm{Ca}^{2+}$ dependance of release machinery was, however, not in focus of the present study. Alongside transmitter rebinding and spillover, asynchronous 
release is a major mechanism contributing to activity-dependent changes in inhibitory duration.

\section{EFFICACY OF SLOW INHIBITION}

Neurons in the auditory brainstem generate APs with an extraordinary temporal accuracy required for the computation of sound source location (for review see, Grothe et al., 2010). In the binaural nuclei of the superior olivary complex, the fast and mainly glycinergic inhibition may contribute by providing high precision phasic suppression of excitatory conductance (Awatramani et al., 2004; Magnusson et al., 2005; Chirila et al., 2007; Couchman et al., 2010; Roberts et al., 2013, 2014; Myoga et al., 2014). The monaural neurons in the mammalian cochlear nucleus, such as bushy cells of the AVCN and the granule cells of the DCN, on the other hand, utilize slow inhibition characterized by an activity-dependent conductance build-up (Balakrishnan et al., 2009; Xie and Manis, 2013). In vivo, the onset of acoustically evoked inhibition on SBCs is delayed compared to the excitation (Kuenzel et al., 2011; Nerlich et al., 2014) which cannot be solely explained by the polysynaptic inhibitory pathway causing a delay of just a few milliseconds (Smith and Rhode, 1989; Wickesberg and Oertel, 1990; Saint Marie et al., 1991; Ostapoff et al., 1997; Campagnola and Manis, 2014). Rather, the new data suggest that the slow time course of inhibition is predominantly determined by the receptor kinetics and transmitter clearance during short stimuli, whereas long duration or high frequency stimulation additionally engage spillover of glycine and asynchronous release of both glycine and GABA to prolong IPSCs. The contribution of these synaptic mechanisms can explain the slow onset of inhibition observed in vivo. With increasing sound intensity, the dynamic adjustment of inhibitory potency through synergistic glycine-GABA signaling (Nerlich et al., 2014) would ensure effective integration with strong and coincident excitatory inputs leading to non-monotonic rate-level functions and improved temporal precision of the SBC output (Kopp-Scheinpflug et al., 2002; Dehmel et al., 2010; Kuenzel et al., 2011). Consistent with this hypothesis, a modeling study of SBC inhibition with fast IPSC kinetics as those measured in AVCN T-stellate cells impaired the temporal precision of spiking (Xie and Manis, 2013). Thus, the activity-dependance of slow inhibition seems to be a critical factor for precise temporal processing in SBCs.

\section{ACKNOWLEDGMENTS}

This work was supported by the DFG grants MI 954/2-1 (Ivan Milenkovic, Jana Nerlich), MI 954/1-1 (Ivan Milenkovic), RU 390/19-1 (Rudolf Rübsamen, Jana Nerlich), GRK 1097 (Jana Nerlich, C.K.), the NIH grant NIH/NIDCD R01-DC008989 (R. Michael Burger, Jana Nerlich), and a DAAD scholarship to Jana Nerlich. The authors thank Stefan N. Oline for helpful comments on an earlier version of the manuscript.

\section{REFERENCES}

Apostolides, P. F., and Trussell, L. O. (2013). Rapid, activity-independent turnover of vesicular transmitter content at a mixed glycine/GABA synapse. J. Neurosci. 33, 4768-4781. doi: 10.1523/JNEUROSCI.5555-12.2013

Apostolides, P. F., and Trussell, L. O. (2014). Chemical synaptic transmission onto superficial stellate cells of the mouse dorsal cochlear nucleus. J. Neurophysiol. 111, 1812-1822. doi: 10.1152/jn.00821.2013
Atluri, P. P., and Regehr, W. G. (1996). Determinants of the time course of facilitation at the granule cell to Purkinje cell synapse. J. Neurosci. 16, 56615671.

Atluri, P. P., and Regehr, W. G. (1998). Delayed release of neurotransmitter from cerebellar granule cells. J. Neurosci. 18, 8214-8227.

Awatramani, G. B., Turecek, R., and Trussell, L. O. (2004). Inhibitory control at a synaptic relay. J. Neurosci. 24, 2643-2647. doi: 10.1523/jneurosci.5144-03.2004

Awatramani, G. B., Turecek, R., and Trussell, L. O. (2005). Staggered development of GABAergic and glycinergic transmission in the MNTB. J. Neurophysiol. 93, 819-828. doi: 10.1152/jn.00798.2004

Balakrishnan, V., Kuo, S. P., Roberts, P. D., and Trussell, L. O. (2009). Slow glycinergic transmission mediated by transmitter pooling. Nat. Neurosci. 12, 286-294. doi: 10.1038/nn.2265

Beato, M. (2008). The time course of transmitter at glycinergic synapses onto motoneurons. J. Neurosci. 28, 7412-7425. doi: 10.1523/JNEUROSCI.0581-08. 2008

Bedet, C., Isambert, M. F., Henry, J. P., and Gasnier, B. (2000). Constitutive phosphorylation of the vesicular inhibitory amino acid transporter in rat central nervous system. J. Neurochem. 75, 1654-1663. doi: 10.1046/j.1471-4159.2000. 0751654.x

Best, A. R., and Regehr, W. G. (2009). Inhibitory regulation of electrically coupled neurons in the inferior olive is mediated by asynchronous release of GABA. Neuron 62, 555-565. doi: 10.1016/j.neuron.2009.04.018

Borst, J. G. (2010). The low synaptic release probability in vivo. Trends Neurosci. 33, 259-266. doi: 10.1016/j.tins.2010.03.003

Bradaïa, A., Schlichter, R., and Trouslard, J. (2004). Role of glial and neuronal glycine transporters in the control of glycinergic and glutamatergic synaptic transmission in lamina X of the rat spinal cord. J. Physiol. 559(Pt. 1), 169-186. doi: 10.1113/jphysiol.2004.068858

Campagnola, L., and Manis, P. B. (2014). A map of functional synaptic connectivity in the mouse anteroventral cochlear nucleus. J. Neurosci. 34, 2214-2230. doi: 10. 1523/JNEUROSCI.4669-13.2014

Campos, M. L., de Cabo, C., Wisden, W., Juiz, J. M., and Merlo, D. (2001). Expression of $\mathrm{GABA}(\mathrm{A})$ receptor subunits in rat brainstem auditory pathways: cochlear nuclei, superior olivary complex and nucleus of the lateral lemniscus. Neuroscience 102, 625-638. doi: 10.1016/s0306-4522(00) 00525-x

Capogna, M., and Pearce, R. A. (2011). GABA A, slow: causes and consequences. Trends Neurosci. 34, 101-112. doi: 10.1016/j.tins.2010.10.005

Chanda, S., and Xu-Friedman, M. A. (2010). A low-affinity antagonist reveals saturation and desensitization in mature synapses in the auditory brain stem. J. Neurophysiol. 103, 1915-1926. doi: 10.1152/jn.00751.2009

Chen, S., and Diamond, J. S. (2002). Synaptically released glutamate activates extrasynaptic NMDA receptors on cells in the ganglion cell layer of rat retina. J. Neurosci. 22, 2165-2173.

Chen, C., and Regehr, W. G. (1999). Contributions of residual calcium to fast synaptic transmission. J. Neurosci. 19, 6257-6266.

Chéry, N., and de Koninck, Y. (1999). Junctional versus extrajunctional glycine and GABA(A) receptor-mediated IPSCs in identified lamina I neurons of the adult rat spinal cord. J. Neurosci. 19, 7342-7355.

Chirila, F. V., Rowland, K. C., Thompson, J. M., and Spirou, G. A. (2007). Development of gerbil medial superior olive: integration of temporally delayed excitation and inhibition at physiological temperature. J. Physiol. 584(Pt. 1), 167-190. doi: 10.1113/jphysiol.2007.137976

Coleman, W. L., Fischl, M. J., Weimann, S. R., and Burger, R. M. (2011). GABAergic and glycinergic inhibition modulate monaural auditory response properties in the avian superior olivary nucleus. J. Neurophysiol. 105, 2405-2420. doi: 10. 1152/jn.01088.2010

Couchman, K., Grothe, B., and Felmy, F. (2010). Medial superior olivary neurons receive surprisingly few excitatory and inhibitory inputs with balanced strength and short-term dynamics. J. Neurosci. 30, 17111-17121. doi: 10. 1523/JNEUROSCI.1760-10.2010

Dehmel, S., Kopp-Scheinpflug, C., Weick, M., Dörrscheidt, G. J., and Rübsamen, R. (2010). Transmission of phase-coupling accuracy from the auditory nerve to spherical bushy cells in the Mongolian gerbil. Hear. Res. 268, 234-249. doi: 10. 1016/j.heares.2010.06.005

Diamond, J. S. (2001). Neuronal glutamate transporters limit activation of NMDA receptors by neurotransmitter spillover on CA1 pyramidal cells. J. Neurosci. 21, 8328-8338. 
Dugué, G. P., Dumoulin, A., Triller, A., and Dieudonné, S. (2005). Targetdependent use of co-released inhibitory transmitters at central synapses. J. Neurosci. 25, 6490-6498. doi: 10.1523/jneurosci.1500-05.2005

Dumoulin, A., Triller, A., and Dieudonné, S. (2001). IPSC kinetics at identified GABAergic and mixed GABAergic and glycinergic synapses onto cerebellar Golgi cells. J. Neurosci. 21, 6045-6057.

Eggermann, E., Bucurenciu, I., Goswami, S. P., and Jonas, P. (2012). Nanodomain coupling between $\mathrm{Ca}^{2+}$ channels and sensors of exocytosis at fast mammalian synapses. Nat. Rev. Neurosci. 13, 7-21. doi: 10.1038/nrn3125

Eyre, M. D., Renzi, M., Farrant, M., and Nusser, Z. (2012). Setting the time course of inhibitory synaptic currents by mixing multiple GABA(A) receptor $\alpha$ subunit isoforms. J. Neurosci. 32, 5853-5867. doi: 10.1523/JNEUROSCI.6495-11. 2012

Farrant, M., and Nusser, Z. (2005). Variations on an inhibitory theme: phasic and tonic activation of GABA(A) receptors. Nat. Rev. Neurosci. 6, 215-229. doi: 10. 1038/nrn1625

Fischl, M. J., Weimann, S. R., Kearse, M. G., and Burger, R. M. (2014). Slowly emerging glycinergic transmission enhances inhibition in the sound localization pathway of the avian auditory system. J. Neurophysiol. 111, 565-572. doi: 10. 1152/jn.00640.2013

Friauf, E., Hammerschmidt, B., and Kirsch, J. (1997). Development of adult-type inhibitory glycine receptors in the central auditory system of rats. J. Comp. Neurol. 385, 117-134. doi: 10.1002/(sici)1096-9861(19970818)385:1<117::aidcne7>3.0.co;2-5

Gai, Y., and Carney, L. H. (2008). Influence of inhibitory inputs on rate and timing of responses in the anteroventral cochlear nucleus. J. Neurophysiol. 99, 10771095. doi: 10.1152/jn.00708.2007

Gingrich, K. J., Roberts, W. A., and Kass, R. S. (1995). Dependence of the GABAA receptor gating kinetics on the alpha-subunit isoform: implications for structure-function relations and synaptic transmission. J. Physiol. 489(Pt. 2), 529-543.

Goda, Y., and Stevens, C. F. (1994). Two components of transmitter release at a central synapse. Proc. Natl. Acad. Sci. U S A 91, 12942-12946. doi: 10.1073/pnas. 91.26.12942

González-Forero, D., and Alvarez, F. J. (2005). Differential postnatal maturation of GABAA, glycine receptor and mixed synaptic currents in Renshaw cells and ventral spinal interneurons. J. Neurosci. 25, 2010-2023. doi: 10.1523/jneurosci. 2383-04.2005

Grothe, B., Pecka, M., and McAlpine, D. (2010). Mechanisms of sound localization in mammals. Physiol. Rev. 90, 983-1012. doi: 10.1152/physrev.00026.2009

Hefft, S., and Jonas, P. (2005). Asynchronous GABA release generates long-lasting inhibition at a hippocampal interneuron-principal neuron synapse. Nat. Neurosci. 8, 1319-1328. doi: 10.1038/nn1542

Husson, Z., Rousseau, C. V., Broll, I., Zeilhofer, H. U., and Dieudonné, S. (2014). Differential GABAergic and glycinergic inputs of inhibitory interneurons and purkinje cells to principal cells of the cerebellar nuclei. J. Neurosci. 34, 94189431. doi: 10.1523/JNEUROSCI.0401-14.2014

Isaacson, J. S., and Walmsley, B. (1996). Amplitude and time course of spontaneous and evoked excitatory postsynaptic currents in bushy cells of the anteroventral cochlear nucleus. J. Neurophysiol. 76, 1566-1571.

Jonas, P., Bischofberger, J., and Sandkühler, J. (1998). Corelease of two fast neurotransmitters at a central synapse. Science 281, 419-424. doi: 10.1126/science.281. 5375.419

Jones, M. V., and Westbrook, G. L. (1996). The impact of receptor desensitization on fast synaptic transmission. Trends Neurosci. 19, 96-101. doi: 10.1016/s01662236(96)80037-3

Joris, P. X., Carney, L. H., Smith, P. H., and Yin, T. C. (1994). Enhancement of neural synchronization in the anteroventral cochlear nucleus. I. Responses to tones at the characteristic frequency. J. Neurophysiol. 71, 1022-1036.

Keller, A. F., Coull, J. A., Chery, N., Poisbeau, P., and De Koninck, Y. (2001). Regionspecific developmental specialization of GABA-glycine cosynapses in laminas III of the rat spinal dorsal horn. J. Neurosci. 21, 7871-7880.

Keros, S., and Hablitz, J. J. (2005). Subtype-specific GABA transporter antagonists synergistically modulate phasic and tonic GABAA conductances in rat neocortex. J. Neurophysiol. 94, 2073-2085. doi: 10.1152/jn.00520.2005

Kopp-Scheinpflug, C., Dehmel, S., Dörrscheidt, G. J., and Rübsamen, R. (2002). Interaction of excitation and inhibition in anteroventral cochlear nucleus neurons that receive large endbulb synaptic endings. J. Neurosci. 22, 1100411018.
Kramer, F., Griesemer, D., Bakker, D., Brill, S., Franke, J., Frotscher, E., et al. (2014). Inhibitory glycinergic neurotransmission in the mammalian auditory brainstem upon prolonged stimulation: short-term plasticity and synaptic reliability. Front. Neural Circuits 8:14. doi: 10.3389/fncir.2014.00014

Kuenzel, T., Borst, J. G., and van der Heijden, M. (2011). Factors controlling the input-output relationship of spherical bushy cells in the gerbil cochlear nucleus. J. Neurosci. 31, 4260-4273. doi: 10.1523/JNEUROSCI.5433-10. 2011

Kuhlmann, L., Burkitt, A. N., Paolini, A., and Clark, G. M. (2002). Summation of spatiotemporal input patterns in leaky integrate-and-fire neurons: application to neurons in the cochlear nucleus receiving converging auditory nerve fiber input. J. Comput. Neurosci. 12, 55-73. doi: 10.1023/A:1014994113776

Kullmann, D. M., Ruiz, A., Rusakov, D. M., Scott, R., Semyanov, A., and Walker, M. C. (2005). Presynaptic, extrasynaptic and axonal GABAA receptors in the CNS: where and why? Prog. Biophys. Mol. Biol. 87, 33-46. doi: 10.1016/j. pbiomolbio.2004.06.003

Kuo, S. P., Bradley, L. A., and Trussell, L. O. (2009). Heterogeneous kinetics and pharmacology of synaptic inhibition in the chick auditory brainstem. J. Neurosci. 29, 9625-9634. doi: 10.1523/JNEUROSCI.0103-09.2009

Lu, T., Rubio, M. E., and Trussell, L. O. (2008). Glycinergic transmission shaped by the corelease of GABA in a mammalian auditory synapse. Neuron 57, 524-535. doi: 10.1016/j.neuron.2007.12.010

Lu, T., and Trussell, L. O. (2000). Inhibitory transmission mediated by asynchronous transmitter release. Neuron 26, 683-694. doi: 10.1016/s08966273(00)81204-0

Magnusson, A. K., Kapfer, C., Grothe, B., and Koch, U. (2005). Maturation of glycinergic inhibition in the gerbil medial superior olive after hearing onset. J. Physiol. 568(Pt. 2), 497-512. doi: 10.1113/jphysiol.2005.094763

McIntire, S. L., Reimer, R. J., Schuske, K., Edwards, R. H., and Jorgensen, E. M. (1997). Identification and characterization of the vesicular GABA transporter. Nature 389, 870-876.

Meinrenken, C. J., Borst, J. G., and Sakmann, B. (2002). Calcium secretion coupling at calyx of held governed by nonuniform channel-vesicle topography. J. Neurosci. 22, 1648-1667.

Monsivais, P., Yang, L., and Rubel, E. W. (2000). GABAergic inhibition in nucleus magnocellularis: implications for phase locking in the avian auditory brainstem. J. Neurosci. 20, 2954-2963.

Myoga, M. H., Lehnert, S., Leibold, C., Felmy, F., and Grothe, B. (2014). Glycinergic inhibition tunes coincidence detection in the auditory brainstem. Nat. Commun. 5:3790. doi: 10.1038/ncomms4790

Nerlich, J., Kuenzel, T., Keine, C., Korenic, A., Rübsamen, R., and Milenkovic, I. (2014). Dynamic fidelity control to the central auditory system: synergistic glycine/GABAergic inhibition in the cochlear nucleus. J. Neurosci. 34, 1160411620. doi: 10.1523/jneurosci.0719-14.2014

Nicol, M. J., and Walmsley, B. (2002). Ultrastructural basis of synaptic transmission between endbulbs of Held and bushy cells in the rat cochlear nucleus. J. Physiol. 539(Pt. 3), 713-723. doi: 10.1113/jphysiol.2001.012972

Nusser, Z., Sieghart, W., and Somogyi, P. (1998). Segregation of different GABAA receptors to synaptic and extrasynaptic membranes of cerebellar granule cells. J. Neurosci. 18, 1693-1703.

O'Brien, J. A., and Berger, A. J. (1999). Cotransmission of GABA and glycine to brain stem motoneurons. J. Neurophysiol. 82, 1638-1641.

Ostapoff, E. M., Benson, C. G., and Saint Marie, R. L. (1997). GABA- and glycineimmunoreactive projections from the superior olivary complex to the cochlear nucleus in guinea pig. J. Comp. Neurol. 381, 500-512. doi: 10.1002/(sici)10969861(19970519)381:4<500::aid-cne9>3.0.c0;2-6

Otis, T. S., Wu, Y. C., and Trussell, L. O. (1996). Delayed clearance of transmitter and the role of glutamate transporters at synapses with multiple release sites. J. Neurosci. 16, 1634-1644.

Overstreet, L. S., and Westbrook, G. L. (2003). Synapse density regulates independence at unitary inhibitory synapses. J. Neurosci. 23, 2618-2626.

Paolini, A. G., FitzGerald, J. V., Burkitt, A. N., and Clark, G. M. (2001). Temporal processing from the auditory nerve to the medial nucleus of the trapezoid body in the rat. Hear. Res. 159, 101-116. doi: 10.1016/s0378-5955(01)00327-6

Piechotta, K., Weth, F., Harvey, R. J., and Friauf, E. (2001). Localization of rat glycine receptor alphal and alpha2 subunit transcripts in the developing auditory brainstem. J. Comp. Neurol. 438, 336-352. doi: 10.1002/cne.1319.abs

Protti, D. A., Gerschenfeld, H. M., and Llano, I. (1997). GABAergic and glycinergic IPSCs in ganglion cells of rat retinal slices. J. Neurosci. 17, 6075-6085. 
Roberts, M. T., Seeman, S. C., and Golding, N. L. (2013). A mechanistic understanding of the role of feedforward inhibition in the mammalian sound localization circuitry. Neuron 78, 923-935. doi: 10.1016/j.neuron.2013.04.022

Roberts, M. T., Seeman, S. C., and Golding, N. L. (2014). The relative contributions of MNTB and LNTB neurons to inhibition in the medial superior olive assessed through single and paired recordings. Front. Neural Circuits 8:49. doi: 10 . 3389/fncir.2014.00049

Rousseau, F., Aubrey, K. R., and Supplisson, S. (2008). The glycine transporter GlyT2 controls the dynamics of synaptic vesicle refilling in inhibitory spinal cord neurons. J. Neurosci. 28, 9755-9768. doi: 10.1523/jneurosci.0509-08.2008

Rousseau, C. V., Dugué, G. P., Dumoulin, A., Mugnaini, E., Dieudonné, S., and Diana, M. A. (2012). Mixed inhibitory synaptic balance correlates with glutamatergic synaptic phenotype in cerebellar unipolar brush cells. J. Neurosci. 32, 4632-4644. doi: 10.1523/jneurosci.5122-11.2012

Russier, M., Kopysova, I. L., Ankri, N., Ferrand, N., and Debanne, D. (2002). GABA and glycine co-release optimizes functional inhibition in rat brainstem motoneurons in vitro. J. Physiol. 541(Pt. 1), 123-137. doi: 10.1113/jphysiol. 2001.016063

Ryugo, D. K., and Sento, S. (1991). Synaptic connections of the auditory nerve in cats: relationship between endbulbs of held and spherical bushy cells. J. Comp. Neurol. 305, 35-48. doi: 10.1002/cne.903050105

Saint Marie, R. L., Benson, C. G., Ostapoff, E. M., and Morest, D. K. (1991). Glycine immunoreactive projections from the dorsal to the anteroventral cochlear nucleus. Hear. Res. 51, 11-28. doi: 10.1016/0378-5955(91) 90003-r

Sato, K., Kuriyama, H., and Altschuler, R. A. (1995). Expression of glycine receptor subunits in the cochlear nucleus and superior olivary complex using non-radioactive in-situ hybridization. Hear. Res. 91, 7-18. doi: 10.1016/03785955(95)00156-5

Seddik, R., Schlichter, R., and Trouslard, J. (2007). Corelease of GABA/glycine in lamina-X of the spinal cord of neonatal rats. Neuroreport 18, 1025-1029. doi: 10. 1097/wnr.0b013e3281667c0c

Smith, P. H., and Rhode, W. S. (1989). Structural and functional properties distinguish two types of multipolar cells in the ventral cochlear nucleus. J. Comp. Neurol. 282, 595-616. doi: 10.1002/cne.902820410

Song, I., Volynski, K., Brenner, T., Ushkaryov, Y., Walker, M., and Semyanov, A. (2013). Different transporter systems regulate extracellular GABA from vesicular and non-vesicular sources. Front. Cell. Neurosci. 7:23. doi: 10.3389/fncel. 2013.00023

Szabadics, J., Tamás, G., and Soltesz, I. (2007). Different transmitter transients underlie presynaptic cell type specificity of GABAA,slow and GABAA,fast. Proc. Natl. Acad. Sci. U S A 104, 14831-14836. doi: 10.1073/pnas.07072 04104

Takahashi, T., Momiyama, A., Hirai, K., Hishinuma, F., and Akagi, H. (1992). Functional correlation of fetal and adult forms of glycine receptors with developmental changes in inhibitory synaptic receptor channels. Neuron 9, 1155-1161. doi: 10.1016/0896-6273(92)90073-m

Tang, Z.-Q., Dinh, E. H., Shi, W., and Lu, Y. (2011). Ambient GABA-activated tonic inhibition sharpens auditory coincidence detection via a depolarizing shunting mechanism. J. Neurosci. 31, 6121-6131. doi: 10.1523/jneurosci.4733-10.2011

Tang, Z.-Q., and Lu, Y. (2012). Two GABAA responses with distinct kinetics in a sound localization circuit. J. Physiol. 590(Pt. 16), 3787-3805. doi: 10. 1113/jphysiol.2012.230136

Thomas, C. G., Tian, H., and Diamond, J. S. (2011). The relative roles of diffusion and uptake in clearing synaptically released glutamate change during early postnatal development. J. Neurosci. 31, 4743-4754. doi: 10.1523/jneurosci.595310.2011
Todd, A. J., Watt, C., Spike, R. C., and Sieghart, W. (1996). Colocalization of GABA, glycine and their receptors at synapses in the rat spinal cord. J. Neurosci. 16, 974-982.

Verdoorn, T. A. (1994). Formation of heteromeric gamma-aminobutyric acid type A receptors containing two different alpha subunits. Mol. Pharmacol. 45, 475480.

Veruki, M. L., Gill, S. B., and Hartveit, E. (2007). Spontaneous IPSCs and glycine receptors with slow kinetics in wide-field amacrine cells in the mature rat retina. J. Physiol. 581(Pt. 1), 203-219. doi: 10.1113/jphysiol.2006.127316

Vyleta, N. P., and Jonas, P. (2014). Loose coupling between $\mathrm{Ca} 2+$ channels and release sensors at a plastic hippocampal synapse. Science 343, 665-670. doi: 10 . $1126 /$ science. 1244811

Wang, P., and Slaughter, M. M. (2005). Effects of GABA receptor antagonists on retinal glycine receptors and on homomeric glycine receptor alpha subunits. J. Neurophysiol. 93, 3120-3126. doi: 10.1152/jn.01228.2004

Wentzel, P. R., De Zeeuw, C. I., Holstege, J. C., and Gerrits, N. M. (1993). Colocalization of GABA and glycine in the rabbit oculomotor nucleus. Neurosci. Lett. 164, 25-29. doi: 10.1016/0304-3940(93)90848-f

Wickesberg, R. E., and Oertel, D. (1990). Delayed, frequency-specific inhibition in the cochlear nuclei of mice: a mechanism for monaural echo suppression. J. Neurosci. 10, 1762-1768.

Williams, S. R., Buhl, E. H., and Mody, I. (1998). The dynamics of synchronized neurotransmitter release determined from compound spontaneous IPSCs in rat dentate granule neurones in vitro. J. Physiol. 510(Pt. 2), 477-497. doi: 10.1111/j. 1469-7793.1998.477bk.x

Wojcik, S. M., Katsurabayashi, S., Guillemin, I., Friauf, E., Rosenmund, C., Brose, N., et al. (2006). A shared vesicular carrier allows synaptic corelease of GABA and glycine. Neuron 50, 575-587. doi: 10.1016/j.neuron.2006.04.016

Xie, R., and Manis, P. B. (2013). Target-specific IPSC kinetics promote temporal processing in auditory parallel pathways. J. Neurosci. 33, 1598-1614. doi: 10. 1523/jneurosci.2541-12.2013

Xie, R., and Manis, P. B. (2014). GABAergic and glycinergic inhibitory synaptic transmission in the ventral cochlear nucleus studied in VGAT channelrhodopsin-2 mice. Front. Neural Circuits 8:84. doi: 10.3389/fncir.2014. 00084

Xu-Friedman, M. A., and Regehr, W. G. (2000). Probing fundamental aspects of synaptic transmission with strontium. J. Neurosci. 20, 4414-4422.

Xu-Friedman, M. A., and Regehr, W. G. (2005). Dynamic-clamp analysis of the effects of convergence on spike timing. II. Few synaptic inputs. J. Neurophysiol. 94, 2526-2534. doi: 10.1152/jn.01308.2004

Conflict of Interest Statement: The authors declare that the research was conducted in the absence of any commercial or financial relationships that could be construed as a potential conflict of interest.

Received: 12 September 2014; accepted: 02 December 2014; published online: 23 December 2014.

Citation: Nerlich J, Keine C, Rübsamen R, Burger RM and Milenkovic I (2014) Activity-dependent modulation of inhibitory synaptic kinetics in the cochlear nucleus. Front. Neural Circuits 8:145. doi: 10.3389/fncir.2014.00145

This article was submitted to the journal Frontiers in Neural Circuits.

Copyright (C) 2014 Nerlich, Keine, Rübsamen, Burger and Milenkovic. This is an openaccess article distributed under the terms of the Creative Commons Attribution License $(C C B Y)$. The use, distribution and reproduction in other forums is permitted, provided the original author(s) or licensor are credited and that the original publication in this journal is cited, in accordance with accepted academic practice. No use, distribution or reproduction is permitted which does not comply with these terms. 